\title{
AUTOMATED TERMINUS DETECTION FOR GREENLAND'S PERIPHERAL MARINE-TERMINATING GLACIERS
}

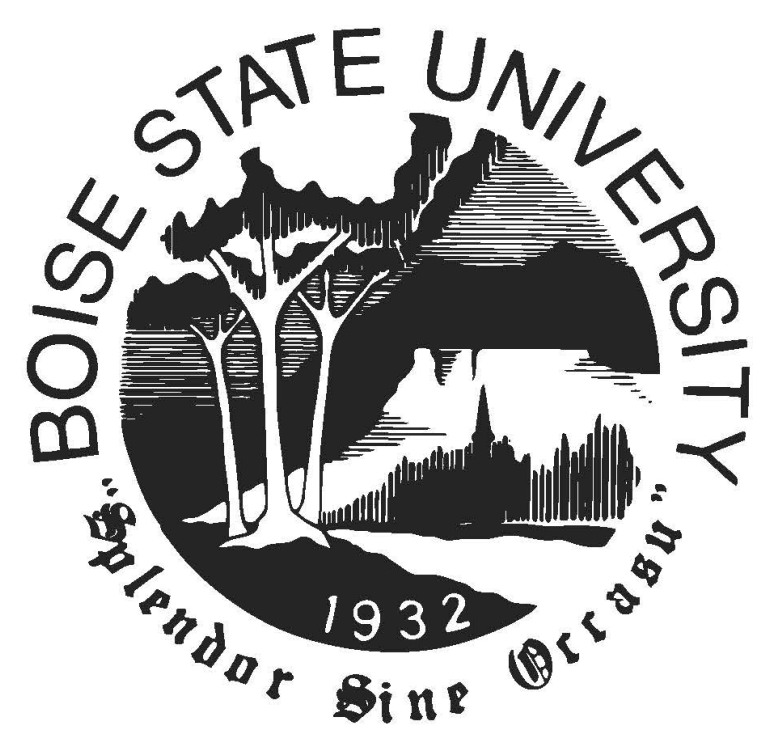

\author{
A thesis \\ submitted in partial fulfillment \\ of the requirements for the degree of \\ Master of Science in Geophysics \\ Boise State University
}

August 2020 
(C) 2020

Julia Liu

ALL RIGHTS RESERVED 
BOISE STATE UNIVERSITY GRADUATE COLLEGE

\section{DEFENSE COMMITTEE AND FINAL READING APPROVALS}

of the thesis submitted by

Julia Liu

Thesis Title: Automated Terminus Detection for Greenland's peripheral Marineterminating Glaciers

Date of Final Oral Examination: $\quad 17$ June 2020

The following individuals read and discussed the thesis submitted by student Julia Liu, and they evaluated the students presentation and response to questions during the final oral examination. They found that the student passed the final oral examination.

Ellyn Enderlin Ph.D. Co-Chair, Supervisory Committee

Andre Khalil Ph.D. Co-Chair, Supervisory Committee

Hans-Peter Marshall Ph.D. Member, Supervisory Committee

The final reading approval of the thesis was granted by Ellyn Enderlin Ph.D., Chair of the Supervisory Committee. The thesis was approved by the Graduate College. 


\section{DEDICATION}

To Mother Earth and all her beautiful ice and snow-covered landscapes. 


\section{ACKNOWLEDGMENT}

This research project is funded by NASA ROSES Cryospheric Grants 80NSSC18K1228 and 80NSSC19K0976. Thank you to my committee members for their guidance throughout this project. Much gratitude to Jacquelyn Bellefontaine for her assistance with compiling the manual glacier terminus delineation dataset and Dr. Alison Cook for providing the terminus boxes drawn over the glaciers. Finally, thank you to the other graduate students at Boise State University and the University of Maine, my friends, and parents for the feedback and encouragement over the last two years. Your support made this all possible. 


\section{AUTOBIOGRAPHICAL SKETCH}

I was born in Provo, UT and raised in Bellevue, WA. After receiving an International Baccalaureate Diploma and graduating from Interlake High School, Bellevue, WA, I attended Dartmouth College in Hanover, NH. At Dartmouth, I discovered my passions for studying ice and remote sensing. After studying Athabasca Glacier in the Columbia Icefield, Canada on the Dartmouth Earth Sciences field program, I became interested in learning about glacier and ice sheet changes. From 2016-2018, I worked as a student GIS analyst delineating glacier area changes for alpine glaciers in the Tian Shan of Xinjiang, China, which later became my undergraduate thesis research project (now published in the Journal of Glaciology). My undergraduate thesis advisors include Robert Hawley and Daniel Lawson. From 2017-2018, I worked as an intern at the US Army Corps of Engineers Cold Regions Research and Engineering Lab (CRREL) in Hanover, NH, performing GIS analysis in support of the Greenland Inland Traverse operations. In addition, I worked as a laboratory assistant in the Dartmouth Ice Core Melting Lab, processing ice cores collected from Greenland and the South Pole. Outside of my research and academic interests, I played rugby on the D1 Varsity Dartmouth Women's Rugby Team and taught snowboarding lessons at the Dartmouth Skiway.

After receiving my B.A. degree in Environmental Earth Sciences with honors from Dartmouth College in 2018, I attended the University of Maine as a Master's student 
where I began working on this research project with Dr. Enderlin and Dr. Khalil. I participated in the Physical Glaciology and Remote Sensing research group led by Dr. Enderlin as well as the Computational Modeling, Analysis of Images, and Numerical Experiments (CompuMAINE) lab led by Dr. Khalil. When Dr. Enderlin began working at Boise State University, I transferred to the MSc. Geophysics program in the Boise State University Geosciences Department where Dr. Marshall joined the research project as a committee member. 


\section{ABSTRACT}

Changes in the length of marine-terminating glaciers strongly influence the mass balance of glaciers, ice caps, and ice sheets. Currently, quantification of glacier length change through measurement of terminus position relies on time-consuming and subjective manual mapping techniques, limiting our ability to understand the dynamics controlling glacier terminus changes. I developed an automated method of mapping glacier terminus positions in satellite imagery using observations from a representative sample of Greenlands peripheral glaciers. The method is adapted from the 2D Wavelet Transform Modulus Maxima (WTMM) segmentation method, which has been used previously for image segmentation in biomedical and other applied science fields. The gradient-based method places edge detection lines along regions with the greatest gradient in intensity in the image, such as the contrast between glacier ice and water or glacier ice and sea ice. I quantified the accuracy of the automated method with reference to a validation dataset consisting of over 500 manual delineations and determined that the automated method is capable of mapping glacier termini over a wide range of image conditions (light to intermediate cloud cover, uniformly dim or bright lighting, etc.) within 1-pixel uncertainty. These time series generated automatically from Landsat images (which have a frequent repeat interval and a long record of images) are capable of resolving sub-seasonal to multiannual temporal patterns as well as regional patterns in terminus change for these glaciers. The 
terminus position time series generated from this automated method indicate that the marine-terminating peripheral glaciers in southeast Greenland undergo synchronous terminus retreat in 2016-17. Initial exploration of regional atmospheric and ocean conditions links this synchronous retreat to subsurface ocean warming and increased surface runoff. 


\section{TABLE OF CONTENTS}

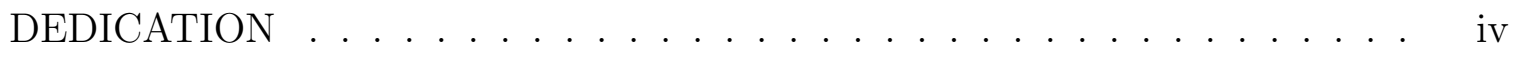

ACKNOWLEDGMENT . . . . . . . . . . . . . . . . . v v

AUTOBIOGRAPHICAL SKETCH ................ . . vi

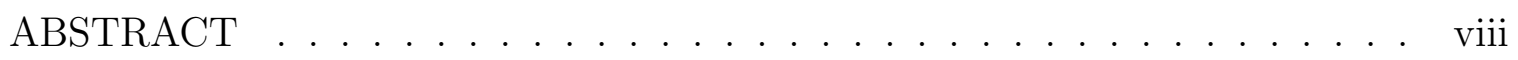

LIST OF FIGURES ........................ xii

LIST OF TABLES .......................... xvi

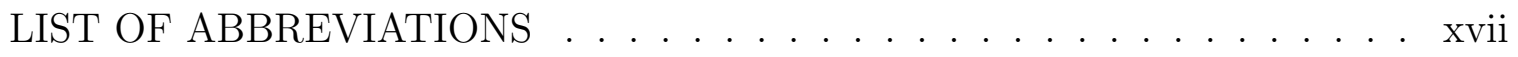

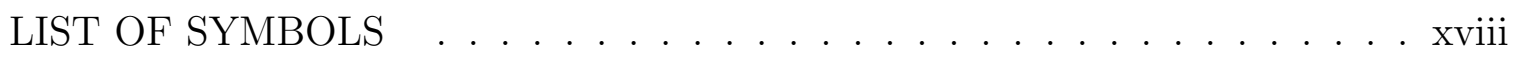

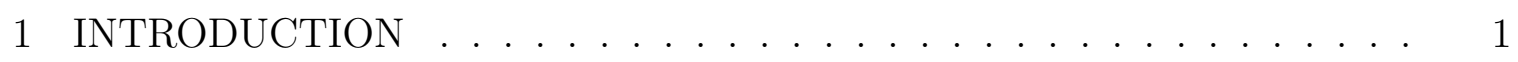

2 AUTOMATED GLACIER TERMINUS DETECTION . . . . . . . . . . . 4

2.1 Brief overview ........................ 5

2.2 Input data . . . . . . . . . . . . . . . . 6

2.3 Image preparation for 2D Wavelet Transform Modulus Maxima (WTMM)

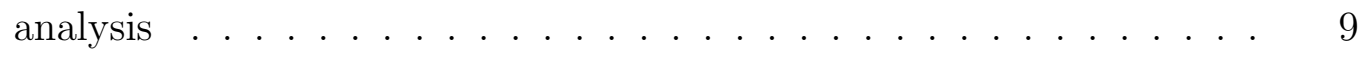


2.3 .1 Bulk image downloads . . . . . . . . . . . . . . . . . . 9

2.3.2 Image rotations and resizing . . . . . . . . . . . . . 11

2.4 Image analysis using the 2D WTMM segmentation method . . . . . 13

2.5 Terminus delineation from the 2D WTMM chains $\ldots \ldots \ldots \ldots$

2.5.1 Masking and filtering of the maxima chains . . . . . . 17

2.5.2 Optimized thresholds for filtering . . . . . . . . . . . 18

2.5.3 Identification of prospective terminus chains . . . . . . . . 19

2.6 Construction of glacier terminus position time series . . . . . . . . 21

2.6.1 Calculation of terminus position along glacier flowlines . . . . 21

2.6.2 Time series filtering . . . . . . . . . . . . . . . . . . 21

2.7 Evaluation of the method performance $\ldots \ldots \ldots \ldots$

2.8 Efficiency advantages over manual delineation . . . . . . . . . . 28

2.9 Conclusions and Future Work . . . . . . . . . . . . . . . . . . . . . . . . 29

3 OCEAN FORCING ON TERMINUS RETREAT IN SOUTHEAST GREEN-

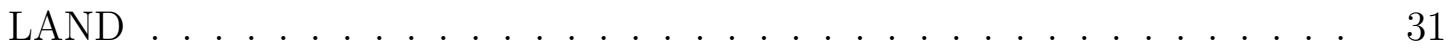

3.1 Introduction . . . . . . . . . . . . . . . . . . . . 31

3.2 Synchronous retreat of southeast peripheral glaciers . . . . . . . 33

3.3 Ocean temperature changes from $2016-2018 \ldots \ldots \ldots \ldots$

3.4 Influence of surface melting $\ldots \ldots \ldots \ldots \ldots$

3.5 Conclusions and Future Work . . . . . . . . . . . . . 37

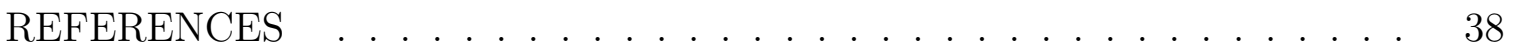




\section{LIST OF FIGURES}

1.1 Modified from Straneo et al. (2012). Summary of the factors influencing mass loss and acceleration on a marine-terminating glacier. The two main components of mass balance are (1) surface mass balance and (2) ice discharge where ice breaks or calves off at the glacier terminus, releasing icebergs. . . . . . . . . . . . . . . .

2.1 Image processing steps: (a) Download subset LS8 panchromatic image using a buffer around the terminus box (blue); (b) Calculate average flow direction (red arrow) using a velocity map; (c) Rotate image so flow direction is due right; (d) Generate maxima chains along regions of the greatest intensity gradients using the 2D WTMM; (e) Examine chains within terminus box extent only (chains brightness corresponds to gradient value); (f) Eliminate other chains based on length, average gradient value, and orientation; (g) Final terminus delineation. Steps (d)-(g) performed at 50 spatial scales. . . . . . . . . . . . .

2.2 Locations of Greenland's marine-terminating peripheral glaciers indicated by white dots in panel (a). Panels (b)-(i) are insets showing terminus boxes drawn over the glaciers' terminus areas to encapsulate terminus position change over the 2000 to 2015 period. . . . . . . . . 
2.3 The 2D WTMM segmentation method on a (a) LS8 panchromatic image over a glacier terminus; (b) Visualization of the derivative of the Gaussian smoothing function used to assess spatial gradients in brightness; (c) Gradient vectors (orange) and maxima points (blue) corresponding to maximal brightness gradients throughout the image at one size scale; (d) Final brightness gradient contours (i.e. maxima chains) shown in blue over smoothed image. . . . . . . . . . .

2.4 3D skeleton plot showing maxima chains generated from 2D WTMM analysis of the underlying cloudy image of a glacier terminus at 50 spatial scales, with spatial scale (a) on the vertical axis. Panels show maxima chains at scale $a=0$ and 12 . Chains capture more detail at smaller scales while smaller-scale features, such as noise, are smoothed at larger scales. . . . . . . . . . . . . . . . .

2.5 Contour plot of the cost as a function of the normalized length and argument thresholds, $C_{L}$ and $C_{A}$, respectively. $C_{m}$ is set as 0.70 . The white contour is the contour boundary separating the lowest cost interval, located at $C_{L}=0.4$ and $C_{A}=0.1 \ldots \ldots \ldots$

2.6 Three flowlines positioned at one-fourth, one-half, and three-fourths of the width of the glaciers terminus box. Terminus position is measured along each flowline as the distance between the intersection of the delineation with the flowline (yellow $X \mathrm{~s}$ ) and the point on the left side of the box (white squares). . . . . . . . . . . . . 
2.7 Landsat-8 time series (2013-2020) of terminus position along the center flowline for four test glaciers. Randolph Glacier Inventory (RGI) ID and center latitude and longitude for the four glaciers shown: (a) RGI50-05.08015 (77.1825 N, 69.9648 W), (b) RGI50-05.08054 (76.8639 $\mathrm{N}, 67.5921^{\circ} \mathrm{W},(\mathrm{c}) \mathrm{RGI50-05.03806}\left(60.9779^{\circ} \mathrm{N}, 43.3386^{\circ} \mathrm{W}\right)$, and (d) RGI50-05.05257 $\left(61.6578^{\circ} \mathrm{N}, 42.7686^{\circ} \mathrm{W}\right) \ldots \ldots \ldots \ldots$

2.8 Examples of automated delineations from a variety of peripheral glaciers and image conditions. Delineations are the most accurate for the following conditions: (a) a clear image with high intensity contrast between glacier ice and darker ocean water, (b) a dim image, (d) a bright image, and (e) an image with thin cloud cover present. The following conditions present challenges to delineation: (c) partial shadow near calving front and (f) thick cloud cover present. Automated delineation yields mixed results for (g) images with sea ice in front of the terminus. 27

3.1 Locations of six marine-terminating peripheral glaciers in southeast Greenland exhibiting anomalous retreat from 2016-2017 (adapted from Catania et al. (2020)). Orange bubbles indicate glaciers near the ocean measurements shown in Fig. 3.2. Panels (a)-(f) show the terminus position time series for the glaciers fit using an 8-term Fourier curve. The period of glacier retreat during the 2016 melt season is highlighted in gray for each time series. . . . . . . . . . . . . . . 
3.2 Annual vertical ocean temperature measurements from Oceans Melting Greenland (OMG) over 2016-2018 near three of the six peripheral glaciers (see Fig. 3.1 for locations). Temperature profiles indicate that subsurface waters $(<200$ meters below sea level) are warmer after 2016 . 36 


\section{LIST OF TABLES}

2.1 Median misfit values $\left(X_{\text {diff }}\right) \pm$ one median of absolute difference (MAD) by image condition for the cross-validation dataset $(n=51)$ and the full dataset $(n=512) . \ldots \ldots \ldots \ldots \ldots$

3.1 P-values from Wilcoxon rank sum tests of terminus positions for adjacent years in each time series. Glaciers are listed by their panel label (a)-(f) from Fig. 3.1. Statistical significance is indicated as follows: for $p>0.05, *$ for $p<0.05, * *$ for $p<0.01, * * *$ for $p<0.001, * * * *$ for $p<0.0001 \ldots \ldots \ldots \ldots \ldots \ldots \ldots \ldots$ 


\section{LIST OF ABBREVIATIONS}

AXCTD Airborne eXpendable Conductivity Temperature Depth

CompuMAINE Computational Modeling, Analysis of Images, and Numerical Experiments

CPU core processing unit

GEEDiT Google Earth Engine Digitisation Tool

GLIMS Global Land Ice Measurements from Space GrIS Greenland

Ice Sheet

InSAR Interferometric Synthetic Aperture Radar OMG Oceans

Melting Greenland

RACMO Regional Atmospheric Climate Model RGI Randolph

Glacier Inventory

Tcl Tool command language

UTM Universal Transverse Mercator

WTMM Wavelet Transform Modulus Maxima 


\section{LIST OF SYMBOLS}

$C_{A} \quad$ normalized threshold defined as the fraction of points in a maxima chain that have left- or right-pointing arguments

$C_{L} \quad$ normalized threshold defined as the fraction of the maximum length of all maxima chains generated for an image

$C_{m} \quad$ normalized threshold defined as the fraction of the maximum average modulus value of all the maxima chains generated for an image

$L \quad$ the length of a maxima chain

$\theta_{v} \quad$ glacier ice flow direction

$a$ the exponent defining the scale of analysis. In pixels, scale $=7 * 2^{a / 10}$ where $a=0,1,2, \ldots, 49$

$a^{-1} \quad$ per year

$m$ the average modulus value for all the maxima points in a maxima chain

$s \quad$ glacier ice speed

$v_{x}, v_{y} \mathrm{x}$ - and $\mathrm{y}$-components of velocity 


\section{CHAPTER 1: INTRODUCTION}

Glacier mass loss and thermal expansion are the two largest contributors to contemporary sea level rise, which critically impacts coastal populations (IPCC, 2014). Global sea level rise is of major concern to coastal systems, with many communities focusing on infrastructure adaptations (IPCC, 2014). Estimates of global sea level rise will be critical to risk assessment and the development of adaptation strategies. In addition, the fresh glacial meltwater directly impacts marine ecosystems and regional ocean circulation patterns (Straneo et al., 2011; Meire et al., 2017; Nishizawa et al., 2020). While the sea level rise contribution of the Greenland Ice Sheet (GrIS) and its major outlet glaciers have been well-monitored (Enderlin et al., 2014; King et al., 2018), mass loss data are much sparser for the glaciers around Greenland's periphery.

These peripheral glaciers are estimated to have lost approximately $38 \mathrm{Gt} / \mathrm{yr}$ from 2003-2009, making them the second largest contributor to glacier mass loss outside of the ice sheets (Gardner et al., 2013). The difference between total mass loss estimates and modeled surface mass balance anomalies over this time period suggests that mass loss due to increased ice discharge is on the order of 10-20 Gt/yr, but no ice discharge estimates have been made to confirm this estimate.

Changes to the terminus position of marine-terminating glaciers influences glacier mass balance through direct loss of mass at the calving front. In addition, loss of 


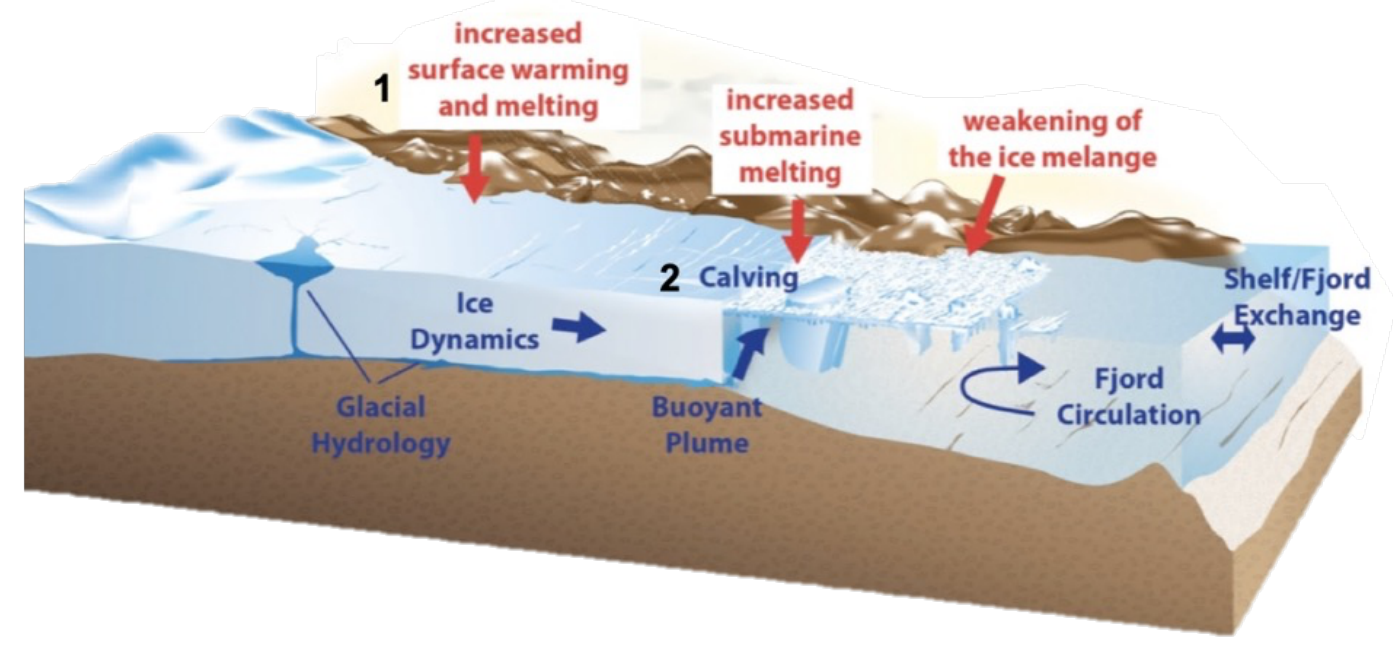

Figure 1.1 Modified from Straneo et al. (2012). Summary of the factors influencing mass loss and acceleration on a marine-terminating glacier. The two main components of mass balance are (1) surface mass balance and (2) ice discharge where ice breaks or calves off at the glacier terminus, releasing icebergs.

mass at the glacier terminus modulates the forces governing glacier ice flow (Howat et al., 2005, 2008). Figure 1.1, adapted from Straneo et al. (2012), shows the various factors influencing glacier mass loss on tidewater glaciers. Loss of resistive stress can result in acceleration and thinning of the ice, contributing further to dynamic glacier mass loss (Howat et al., 2008; Moon and Joughin, 2008; McFadden et al., 2011; Carr et al., 2013; Cook et al., 2016, 2019; Catania et al., 2020). Long-term changes in ice flow may result from rapid changes in glacier terminus position, as discussed in Howat et al. (2010). Since glacier calving is a stochastic process that potentially triggers large dynamic changes, studies of glacier dynamics benefit from measurements of terminus position at fine temporal resolution. Measuring terminus changes at sub-seasonal timescales at minimum is required to resolve glacier dynamic responses. 
Prior studies investigating glacier terminus position change and its influence on dynamics and mass loss relied on manual mapping of glacier calving fronts, which is time-intensive and dependent on human interpretation. The accuracy of these manual delineations may drift over time for human analysts and may result in biases when terminus positions delineated by multiple analysts are considered. Automated methods for delineating glacier calving fronts are more efficient, repeatable, and objective. An automated approach will allow for efficient and accurate measurements of glacier terminus position at fine temporal scales. With an efficient, automated method, investigating peripheral glacier dynamics will not be as effort-limited as a manual approach, which is generally limited in the number of glaciers analyzed, temporal resolution, and/or temporal range.

In order to quantify changes in length of hundreds of marine-terminating peripheral glaciers, I adapt an image segmentation technique used previously in a wide variety of applied science fields called the 2D WTMM segmentation method (Khalil et al., 2007). I apply the method to analyze panchromatic optical satellite images from the Landsat mission, chosen for their high temporal and radiometric resolutions, of marine-terminating glaciers. This gradient-based and multi-scale automated delineation method allows for detailed analysis of glacier terminus position changes at hundreds to thousands of time points. With the delineations from this method, I generate time series of terminus positions for these peripheral glaciers, spanning a broad spectrum of geometries, environmental conditions, and retreat patterns. 


\section{CHAPTER 2:}

\section{AUTOMATED GLACIER TERMINUS DETECTION}

This chapter describes the automated workflow used to delineate the peripheral glaciers' termini and calculate terminus positions. I developed this workflow to automatically analyze available Landsat images over the 641 marine-terminating peripheral glaciers in Greenland (locations shown in Figure 2.2). While the automated method currently performs analysis on the panchromatic band of optical imagery and reprojects data to the Greenland Polar Stereographic projection, it could be modified to analyze other types of satellite imagery and in other regions. The automated workflow incorporates the adapted 2D Wavelet Transform Modulus Maxima (WTMM) segmentation method, used previously in a wide variety of applied science fields (see section 2.4). All of the analysis outside of the 2D WTMM segmentation are programmed in Python and the code is compiled in the form of Jupyter notebooks. The 2D WTMM analysis is performed in a Xsmurf, a software used for wavelet analysis in the Computational Modeling, Analysis of Images, and Numerical Experiments (CompuMAINE) Lab at the University of Maine. Xsmurf runs scripts written in the Tool command language (Tcl). Commands to run the Tcl scripts in Xsmurf are im-

plemented through iPython in within the Jupyter notebooks, which interfaces with 
the command line through various modules (e.g. subprocess, os, etc.).

\subsection{Brief overview}

Figure 2.1 shows the following image processing steps described. The automated method uses georeferenced boxes drawn over each of glaciers' terminus to bulk download corresponding subsets of Landsat-8 images available through Amazon Web Services (Fig. 2.1a, section 2.3.1). Using an ice-sheet-wide velocity raster, the method calculates the representative glacier flow direction (Fig. 2.1b). The images are then automatically rotated by this flow direction so that their flow is to the right, which sets up a common frame of reference for analyzing terminus position changes (Fig. 2.1c, section 2.3.2). After the initial image processing, these rotated image subsets are automatically analyzed using the 2D WTMM segmentation method, which calculates gradients in pixel intensity values throughout each image at multiple spatial scales (Fig. 2.1d, section 2.4). The method places edge detection lines where the intensity gradients are maximal, i.e. in regions where the intensity contrast is high, such as the boundary between glacier ice and sea ice or glacier ice and open water. From these edge detection lines, the line that is most likely to represent a delineation of the glacier terminus is determined using line attributes such as its length, orientation, and associated gradient value within the terminus box (Fig. 2.1e,f, section 2.5.1). From these chosen terminus delineations (Fig. 2.1g), the method calculates terminus position with reference to innermost side of the terminus box along three glacier flowlines (section 2.6.1). The terminus position time series generated for each glacier is then filtered using the maximum flow speeds of the glacier (section 2.6.2). The final outputs are the filtered time series of terminus position for each glacier

analyzed, which show terminus position changes at sub-seasonal timescales over the 
Landsat-8 record (2013-2020).

\subsection{Input data}

The sole inputs required for the automated analysis of each peripheral glacier are (1) georeferenced terminus boxes drawn over each glacier's termini, (2) a Greenland Ice Sheet wide velocity dataset, (3) the Landsat scene boundaries, and optionally (4) the glacier's outline available through the RGI.

The 641 glacier terminus boxes were provided by Dr. Alison Cook at the University of Ottawa, who initially created them to cover the glaciers' terminus positions in the years 2000 and 2015 (see Figure 2.2). These were provided in Greenland Polar Stereographic projection (ESPG: 3413), which is a standard Universal Transverse Mercator (UTM) projection for performing analysis in Greenland. Since most of these peripheral glaciers are nameless, they are referred to by their 3-digit box ID from now on (e.g. 001 through 641).

In order to calculate representative glacier flow directions for image rotations and maximum flow speeds for filtering, I use the Greenland MEaSURES multi-year Greenland Ice Sheet Velocity Mosaic, derived from Interferometric Synthetic Aperture Radar (InSAR) data, which provides glacier velocities for all of Greenland's terrestrial ice at 250-meter pixel spacing (Joughin et al., 2017, 2016). Due to the averaging of velocities over multiple years, this velocity dataset produced more accurate glacier velocities in regions of slow-flowing ice than ice velocities derived from a single-year or less of data. For these peripheral glaciers along Greenland's coasts, the velocities are determined from speckle- and feature-tracking, which has errors of 2-3 $m a^{-1}$ (Joughin et al., 2016).

The last input for the automated method is the set of RGI glacier outlines 

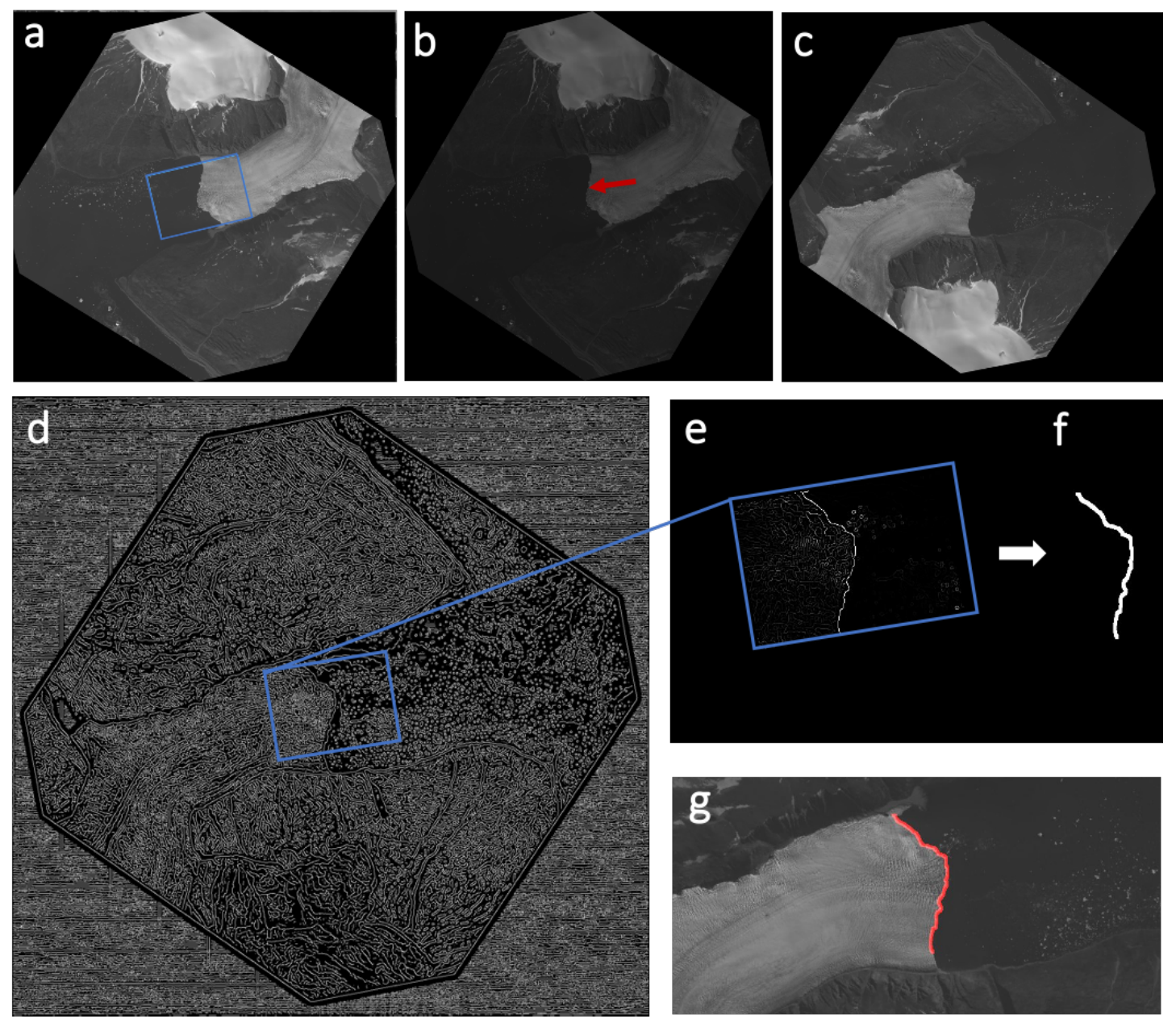

Figure 2.1 Image processing steps: (a) Download subset LS8 panchromatic image using a buffer around the terminus box (blue); (b) Calculate average flow direction (red arrow) using a velocity map; (c) Rotate image so flow direction is due right; (d) Generate maxima chains along regions of the greatest intensity gradients using the 2D WTMM; (e) Examine chains within terminus box extent only (chains brightness corresponds to gradient value); (f) Eliminate other chains based on length, average gradient value, and orientation; (g) Final terminus delineation. Steps (d)-(g) performed at 50 spatial scales. 

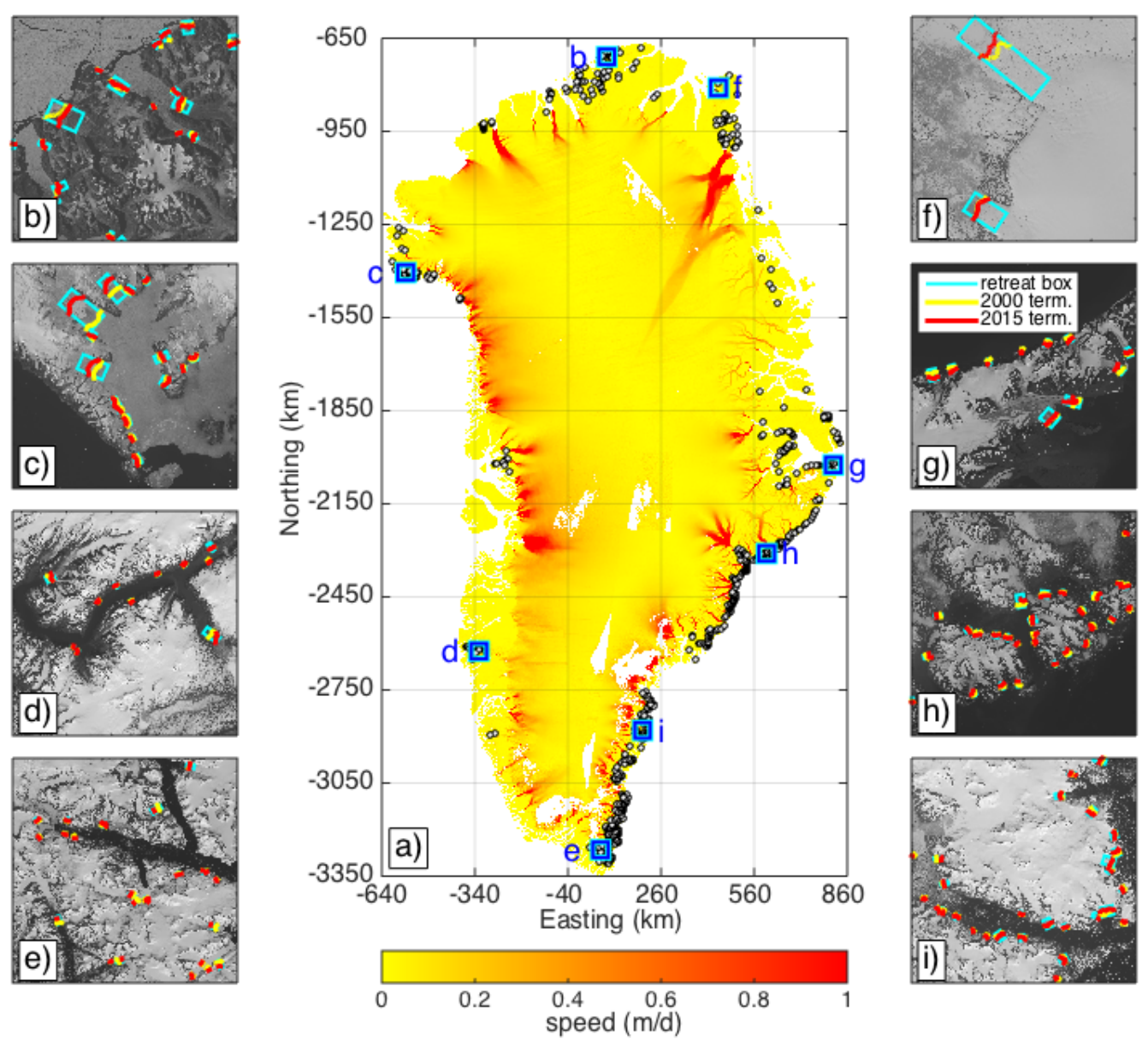

Figure 2.2 Locations of Greenland's marine-terminating peripheral glaciers indicated by white dots in panel (a). Panels (b)-(i) are insets showing terminus boxes drawn over the glaciers' terminus areas to encapsulate terminus position change over the 2000 to 2015 period. 
for each of the glaciers, which are used to crop the velocity raster. The Randolph Glacier Inventory (RGI) is a global inventory of glacier outlines available

through the Global Land Ice Measurements from Space (GLIMS) database, which includes full glacier outlines for least one point in time (RGI, 2017). The glaciers in the RGI are referred to by their RGI identification string. The outlines for all 641 marine-terminating peripheral glaciers were downloaded from the RGI (https: //doi.org/10.7265/N5-RGI-60). For each of the glaciers, the ice velocity raster is cropped to the entire RGI glacier outline rather than the terminus box to improve the accuracy of velocity calculations, since many of the glaciers are small and their boxes only cover a few pixels. However, this is an optional step, and the method automatically uses the boxes if a larger outline is not made available.

\subsection{Image preparation for 2D WTMM analysis}

\subsubsection{Bulk image downloads}

The method I developed automatically uses the georeferenced terminus boxes to determine the overlapping Landsat scenes. For each glacier, the method determines if all the coordinates of the terminus boxes vertices lie within each of the scene boundaries. If so, the Path and Row identifier for the overlapping Landsat scene is stored. Almost all of the glaciers will have multiple overlapping Landsat scenes. Recording all of the overlapping scene Path and Row identifiers allows the method to determine the full suite of available images over the glaciers rather than simply one specified Path-Row combination. Amazon Web Services is a cloud service that provides public access to the ongoing collection of Landsat- 8 satellite imagery including all scenes and metadata (https://registry.opendata.aws/landsat-8/). For all of the available 
images over the glaciers, the metadata file and the image quality band cropped to the terminus box are downloaded. I chose to analyze the panchromatic band due to its greater radiometric and spatial resolution compared to the other Landsat bands. The panchromatic band is available at 15-meter spatial resolution versus 30 meters or greater for the other bands.

The quality band for each Landsat scene contains a classification of the scene, including a cloud confidence assessment for each pixel represented by a value from 0 to 65535 in these 16-bit images. The quality band is cropped to the terminus box to determine cloud presence within the terminus area only. Those pixels with values above ${ }^{\sim} 2800$ correspond to cloud confidence. I set a conservative threshold of 4096 to identify pixels that have a high cloud confidence. If the percentage of pixels within the glacier terminus box that are cloudy (i.e. have high cloud confidence) is greater than 20 percent, the image is not downloaded since clouds obscuring the glacier terminus will prevent an accurate delineation. The Landsat images that pass the cloud assessment proceed onward to the download step.

The Landsat images are cropped prior to download to reduce transfer time, increase image processing computational efficiency, and reduce storage demands. To avoid edge effects on the intensity gradients used to identify the glacier termini, the method creates a buffer with a width corresponding to the maximum terminus box dimension (i.e., whichever is largest out of the length or width) around the terminus box to subset the Landsat images. The method proceeds to bulk download subsets of the non-cloudy images corresponding to the glacier's buffer zone. After the images are downloaded, they are reprojected from the UTM projection to the Greenland Polar Stereographic projection for consistency with the MEaSURES Greenland ve- 
locity dataset. In addition, the image acquisition dates are automatically determined for each downloaded image from the metadata file in order to produce accurate time series from analysis of the images.

\subsubsection{Image rotations and resizing}

Following the approach of Seale et al. (2011), the cropped images were rotated so flow is orientated from left to right, establishing a common reference frame for terminus position analysis. Creating a common frame of reference in which the glacier termini

are approximately vertical in the image space allows the algorithm to identify the glacier terminus using its orientation as a parameter. Image rotation first requires calculation of each glaciers' representative flow direction. I crop the velocity data to the RGI glacier outline or, where the full outline is not available, the terminus box. The data are provided as $x$ and $y$ components of ice velocity. From these components, I calculated the flow directions using the trigonometric relationship:

$$
\theta_{v}=\arctan 2\left(\frac{v_{y}}{v_{x}}\right)
$$

where arctan2 is a mathematical function in Python that allows for the calculation of the arctangent in all four quadrants, resulting in accurate velocity calculations in all directions. Meanwhile, the ice velocity magnitude (i.e. speed) is calculated as

$$
s=\sqrt{v_{x}^{2}+v_{y}^{2}} .
$$

The flow directions and speeds are used to compute the average flow direction weighted by speed. I calculated a weighted flow direction because the glacier ice will have a wide variety of flow directions, especially in the upper reaches of the glacier. 
Glacier flow speeds will be faster near the terminus where flow direction is more representative of the glacier's orientation. Using flow speed as weights in the weighted average calculation will emphasize flow directions corresponding to larger velocities. Manual inspection of the velocities within the terminus boxes indicate irregular, multidirectional flow directions in regions of slow-flowing ice for some glaciers. Since the velocities for these marine-terminating glaciers are derived from speckle- or featuretracking (Joughin et al., 2016), velocities will be more accurate for faster-flowing ice. The velocities determined using feature-tracking are less likely to be accurate for slow-flowing glaciers, so calculating average flow direction using a greater number of velocity pixels will improve the accuracy of the result. Therefore, I use ice velocities within the entire glacier catchment (i.e., cropped to the full RGI outline) to calculate weighted average flow directions for each glacier when the RGI outline is available. For the faster-flowing, larger peripheral glaciers, the weighted average flow directions calculated within just the terminus box may be just as accurate as cropping using the full glacier outline. For each of the glaciers analyzed, I store its weighted average flow direction, maximum flow speed (for time series filtering - see section 2.6.2), and the number of pixels used to calculate the weighted flow direction and speed.

The weighted average flow direction is used to rotate all downloaded, subsetted images as well as the rasterized terminus box subsetted to the same extent. The geographic registration, cropping, reprojection, and rotation of these images may cause them to be of slightly different sizes. In order to perform masking of the 2D WTMM output using the rotated terminus box, all rotated images and the rotated terminus box mask must be the same size. Therefore, after rotation, the rotated images and the rotated terminus box mask are automatically centered and cropped 
to the minimum dimensions of the rotated images and the mask.

\subsection{Image analysis using the 2D WTMM segmentation method}

These rotated satellite images over the glaciers are analyzed using the 2D WTMM segmentation method, developed to perform automatic image segmentation for a variety of images across scientific fields including biomedicine, solar physics, astrobiology, etc. (Khalil et al., 2007; Roland et al., 2009; McAteer et al., 2010; Grant et al., 2010; Kestener et al., 2010; Batchelder et al., 2014; Marin et al., 2017). The 2D WTMM segmentation method is a multi-scale, gradient-based method that identifies contours representing the locally maximal changes in intensity in an image. This is achieved by using the 1st order derivative of the 2D Gaussian smoothing function from Khalil et al. (2007):

$$
\phi(\vec{x})=e^{-\frac{|\vec{x}|^{2}}{2}}
$$

where $\vec{x}$ represents the point $\left(x_{1}, x_{2}\right)$ in the image and $|\vec{x}|=\sqrt{x_{1}^{2}+x_{2}^{2}}$. The continuous wavelet transform of the image $f$ is calculated with respect to the partial derivatives of the smoothing function $\phi$ with respect to $x_{1}$ and $x_{2}$,

$$
\psi_{1}(\vec{x})=\frac{\delta \phi(\vec{x})}{\delta x_{1}} \quad \text { and } \quad \psi_{2}(\vec{x})=\frac{\delta \phi(\vec{x})}{\delta x_{2}}
$$

which amounts to taking the gradient of the convolution of the image with $\phi$ :

$$
T_{\psi}[f](\vec{b}, a)=\left(T_{\psi_{1}}, T_{\psi_{2}}\right)=\nabla(\phi * f)
$$


where $*$ represents convolution, $\vec{b}$ represents the parameter of position, $a$ represents a scale parameter, and $T_{\psi_{1}}, T_{\psi_{2}}$ are the two components of the wavelet transform:

$$
T_{\psi_{1}}[f]=\frac{1}{a^{2}} \int d^{2} \vec{x} \psi_{1}\left(\frac{\vec{x}-\vec{b}}{a}\right) f(\vec{x}) \quad \text { and } \quad T_{\psi_{2}}[f]=\frac{1}{a^{2}} \int d^{2} \vec{x} \psi_{2}\left(\frac{\vec{x}-\vec{b}}{a}\right) f(\vec{x})
$$

The wavelet transform $\left(T_{\psi}\right)$ is a gradient vector which has a magnitude (i.e., wavelet transform modulus, $M_{\psi}$ ) corresponding to the gradient in intensity and a direction (i.e., argument, $A_{\psi}$ ) that points to the highest intensity regions, which are expressed in polar coordinates as:

$$
M_{\psi}[f]=\sqrt{\left(T_{\psi_{1}}[f]^{2}+T_{\psi_{2}}[f]^{2}\right)} \quad \text { and } \quad A_{\psi}[f]=\operatorname{Arg}\left(T_{\psi_{1}}[f]+i T_{\psi_{2}}[f]\right)
$$

Maxima points represent the regions in the image where the intensity gradients (i.e. moduli) are maximal. Wavelet transform modulus maxima (WTMM) are automatically connected along maxima chains that act as edge detection lines for change in intensity (Fig. 2.3). The algorithmic procedure leading to the calculation of these one-pixel thick maxima chains is outlined in the Appendix of McAteer et al. (2010). These maxima chains are generated at 50 spatial scales $(a=0,1,2,3, \ldots, 49)$ that range from the minimum scale required to resolve the wavelet, $7 * 2^{0 / 10}=7$ pixels, to $7 * 2^{49 / 10}=209$ pixels, corresponding to a range of 105 to 3135 meters in these 15-meter resolution images.

In satellite images of the glaciers, maxima chains are generated along regions with high intensity contrasts around the image, such as the contrast between glacier ice and sea ice, open water, and land. The multi-scale analysis allows for delineation of small-scale and large-scale features (Fig. 2.4), which allows the program to adaptively 


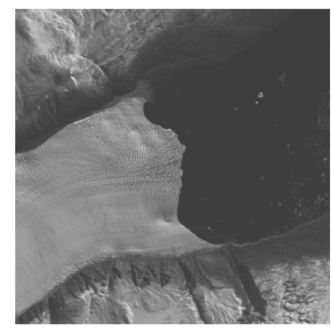

a

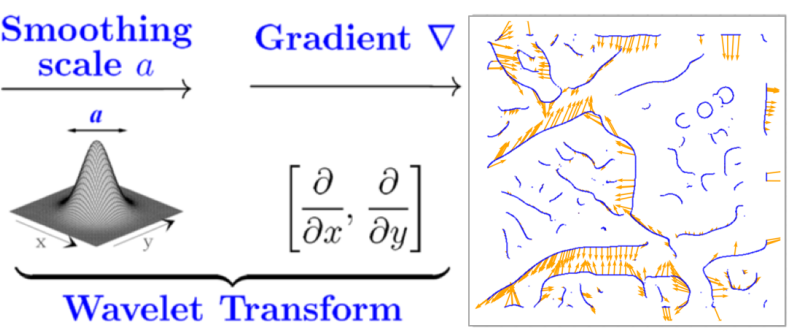

b

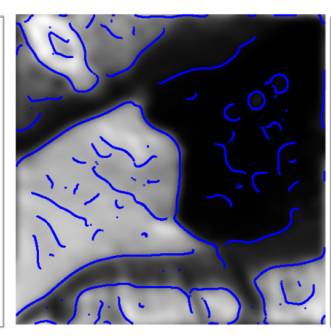

d

Figure 2.3 The 2D WTMM segmentation method on a (a) LS8 panchro-matic image over a glacier terminus; (b) Visualization of the derivative of the Gaussian smoothing function used to assess spatial

gradients in brightness; (c) Gradient vectors (orange) and maxima points (blue) cor-responding to maximal brightness gradients throughout the image at one size scale; (d) Final brightness gradient contours (i.e. maxima chains) shown in blue over smoothed image.

delineate glacier termini of variable sizes, geometries, and environmental conditions without a priori knowledge of the image conditions (Khalil et al., 2007).

The 2D WTMM image analysis is parallelized on the project's machine, an Intel Core i7-8700K computer with $62.8 \mathrm{~Gb}$ of memory and core processing unit (CPU) speed of $3.70 \mathrm{GHz}$. The computer has a total of 12 CPUs. I use 8 CPUs to perform the 2D WTMM analysis, reserving 4 CPUs for other processes on the computer. The 2D WTMM analysis is run in batches of 8 images with each image run on one CPU. Once the batch is completed, the next batch of 8 images are run. Parallelizing the analysis reduced the computation time by an order of magnitude relative to serial processing. On the project machine, 1000 images can be analyzed in under 10 minutes in parallel whereas the same analysis using one CPU would take more than 5 hours. See section 2.8 for a full discussion of efficiency of the automated method. 


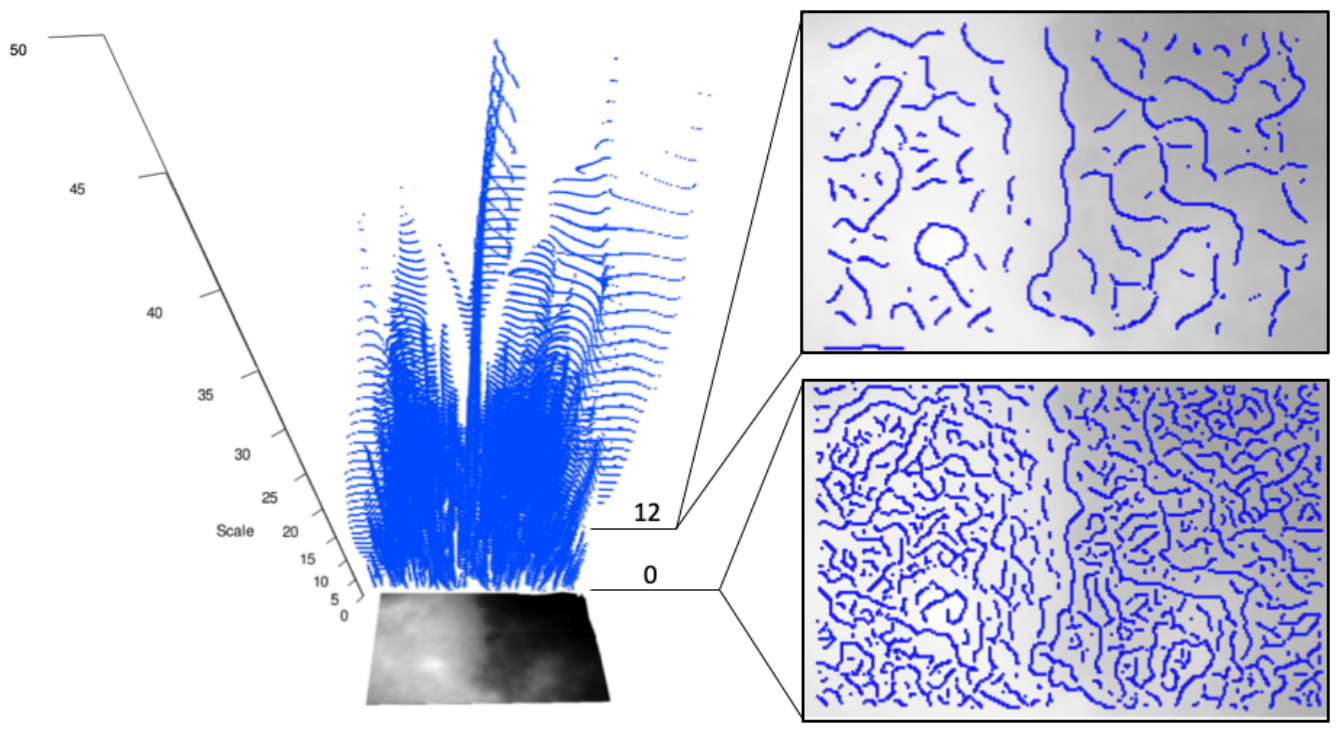

Figure 2.4 3D skeleton plot showing maxima chains generated from 2D WTMM analysis of the underlying cloudy image of a glacier terminus at 50 spatial scales, with spatial scale (a) on the vertical axis. Panels show maxima chains at scale $a=0$ and 12. Chains capture more detail at smaller scales while smaller-scale features, such as noise, are smoothed at larger scales. 


\subsection{Terminus delineation from the 2D WTMM}

\section{chains}

\subsubsection{Masking and filtering of the maxima chains}

Maxima chains across 50 scales output from the 2D WTMM analysis are masked and filtered to objectively identify the chains that are most likely to correspond to the glacier terminus. The rasterized terminus box is used to mask chains outside of the glacier's terminus area. From the remaining chains, the method selects up to five maxima chains most likely to correspond to the glacier terminus using the chains' attributes. The properties for each chain include shape (closed or open), length $(L)$, average modulus value of all maxima points $(m)$, and arguments of the maxima points, which represent the chains orientation. The closed loops are eliminated immediately, since termini are non-connected features. The remaining attributes are extracted at each scale and objective thresholds are applied sequentially to filter the maxima chains. Generally, the maxima chain delineating the glacier terminus will have a high average modulus value (i.e., large intensity contrast) and will be longer than most other chains, especially those corresponding to noise but also including features such as crevasses. Orientation is also used to filter the maxima chains because the glacier terminus should be primarily oriented vertically in the rotated reference frame, such that maxima points will mostly have arguments pointing left or right. The thresholds for orientation/argument and length are normalized by the maximum chain length determined for the image, so that the same threshold can be applied to wide or narrow glaciers. Similarly, the threshold for average modulus value is normalized by the maximum average modulus value determined for the image, so that the same 
threshold can be applied to images with high or low intensity contrasts.

\subsubsection{Optimized thresholds for filtering}

The optimal length, average modulus value, and argument thresholds are objectively determined using an optimization strategy that minimizes a cost function defining the error between automated delineations and 512 manual terminus delineations. The manually-delineated terminus dataset was constructed for 5 sample glaciers with diverse morphologies using the Google Earth Engine Digitisation Tool (GEEDiT) (Lea, 2018), with assistance provided by an undergraduate student from the University of Maine.

For threshold optimization, I randomly allocated $90 \%$ of the manual delineations to a training dataset and the remaining $10 \%$ to a validation dataset for cross validation. Using the training dataset, I constrain the length, modulus, and argument thresholds $\left(C_{L}, C_{m}\right.$, and $C_{A}$, respectively) using an optimization algorithm that minimizes a cost function $(\theta)$ that represents the misfit between the automated delineations and the manual delineations. The misfit for each image (i.e. timepoint) of analysis is the average difference between the automatically- and manually-delineated terminus positions along three glacier flowlines situated at one-fourth, one-half, and

three-fourths of glacier terminus box width (see section 2.6.1 and Fig. 2.6), expressed as the variable $X_{\text {diff }}$ :

$$
X_{\text {diff }}=\frac{\sum_{i=1}^{3}\left|\vec{X}_{\text {auto }}-\vec{X}_{\text {manual }}\right|}{3}
$$

where $\left|X_{\text {auto }}-X_{\text {manual }}\right|$ represents the Euclidean distance between the automaticallyand manually-delineated terminus positions for a given flowline. Refer to section 2.6.1 for the full description of calculation of terminus position along three glacier 
flowlines. The automated-manual misfit for each image $X_{\text {diff }}$ is averaged for a total of $N=460$ images in the training dataset and divided by $F^{3}$, where $F$ is defined as the ratio of the number of intersections with the glacier flowlines (i.e. terminus positions calculated) to the total possible number of intersections $(3 N)$, in the final cost function:

$$
\theta\left(C_{L}, C_{m}, C_{A}\right)=\frac{\sum_{i=1}^{N} X_{d i f f}}{F^{3} N} .
$$

The filtering sequence using the thresholds $C_{m}, C_{L}$, and $C_{A}$ affects the automated delineations of terminus position, and thus the misfit. To identify the optimal sequence, I calculated the cost using a range of 0 to 1 for each of the normalized thresholds, for each combination of filtering order. The sequence that yielded the lowest median cost value was chosen as the optimal order for filtering: average modulus value, length, and then argument. Using this optimal filtering sequence, I computed the costs for combinations of the thresholds $C_{m}, C_{L}$, and $C_{A}$. For $C_{m}$, the cost was minimal at $C_{m}=0.70$ for all combinations of $C_{L}$ and $C_{A}$. Therefore, I set $C_{m}$ to 0.70 and computed costs for a grid of $C_{A}$ and $C_{L}$ values. With $C_{m}$ set to 0.70 , cost value was minimal for $C_{A}=0.1$ and $C_{L}=0.4$ (Fig. 2.5).

\subsubsection{Identification of prospective terminus chains}

The maxima chains that do not satisfy the determined thresholds are eliminated. Chains that do not correspond to the glacier terminus (e.g. delineations of long, highcontrast, and vertical features such as shadow boundaries and sea ice margins) may still remain. These remaining chains across the 50 scales of analysis are aggregated and the five chains that are most likely to delineate the terminus are identified based 


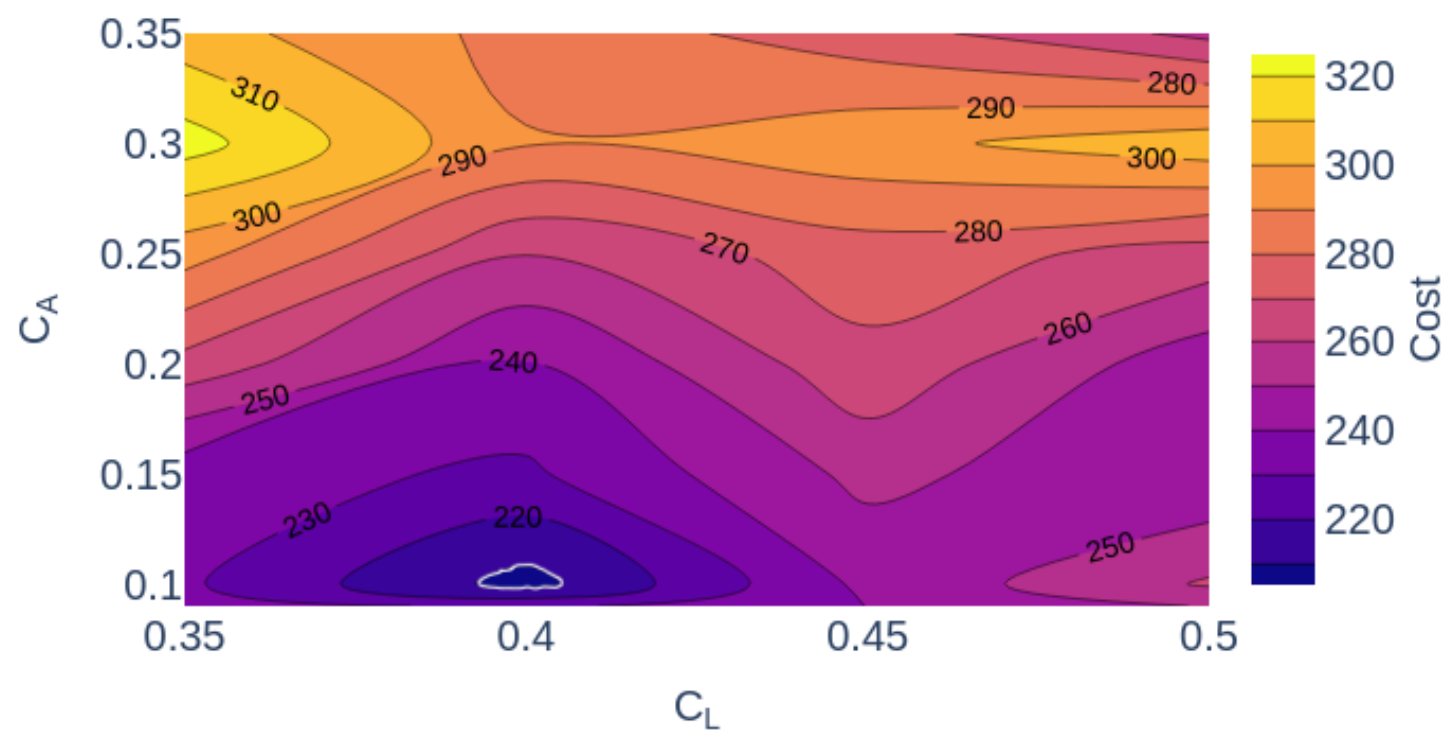

Figure 2.5 Contour plot of the cost as a function of the normalized length and argument thresholds, $C_{L}$ and $C_{A}$, respectively. $C_{m}$ is set as 0.70. The white contour is the contour boundary separating the lowest cost interval, located at $C_{L}=0.4$ and $C_{A}=0.1$.

on the metric:

$$
L \frac{m}{2^{a}},
$$

where $m$ is the chain's average modulus value and $L$ is the chain length, as defined earlier. Average modulus values of the maxima chains increase with scale, $2^{a}$, of WTMM analysis (Batchelder et al., 2014), so the average modulus value is normalized by the scale. The length of the chain and the scale-normalized average modulus value will both be large for a delineation of the glacier terminus compared to delineations of noisy or less prominent features in the image. The method chooses up to five chains from each image with the highest metric values. If fewer than five chains remain after thresholding, then all the remaining chains will be identified as the top chains, which 
will be allowed to pass on to the time series filtering.

\subsection{Construction of glacier terminus position time series}

\subsubsection{Calculation of terminus position along glacier flowlines}

Glacier terminus positions are calculated from the top terminus delineations along three glacier flowlines situated at one-fourth, one-half, and three-fourths of glacier terminus box width (Fig. 2.6). The use of three flowlines at varying distances across the glaciers width optimizes use of the delineations; across-glacier patterns in terminus position can be extracted from complete and partial delineations, enabling analysis of sub-seasonal variations in terminus morphology. This strategy could be expanded by calculating terminus positions along additional flowlines. In contrast, the box method (Walsh et al., 2012; Moon and Joughin, 2008; McNabb and Hock, 2014; Catania et al., 2020) evaluates terminus change in terms of a single area change value.

\subsubsection{Time series filtering}

For each of the top five maxima chains, the method extract the points of intersection with the three glacier flowlines. These points are filtered iteratively using terminus change rates calculated as a forward difference using the median terminus position of the current time point and each terminus position corresponding to the subsequent timepoint. The terminus change rate for each terminus position point is evaluated against the following flow speed condition: if the rate of terminus advance calculated from the delineation is greater than 3 times the maximum glacier speed, this delineation is considered inaccurate and the point is eliminated. Although the glacier terminus cannot advance faster than the rate that the ice is flowing, I use a conser- 


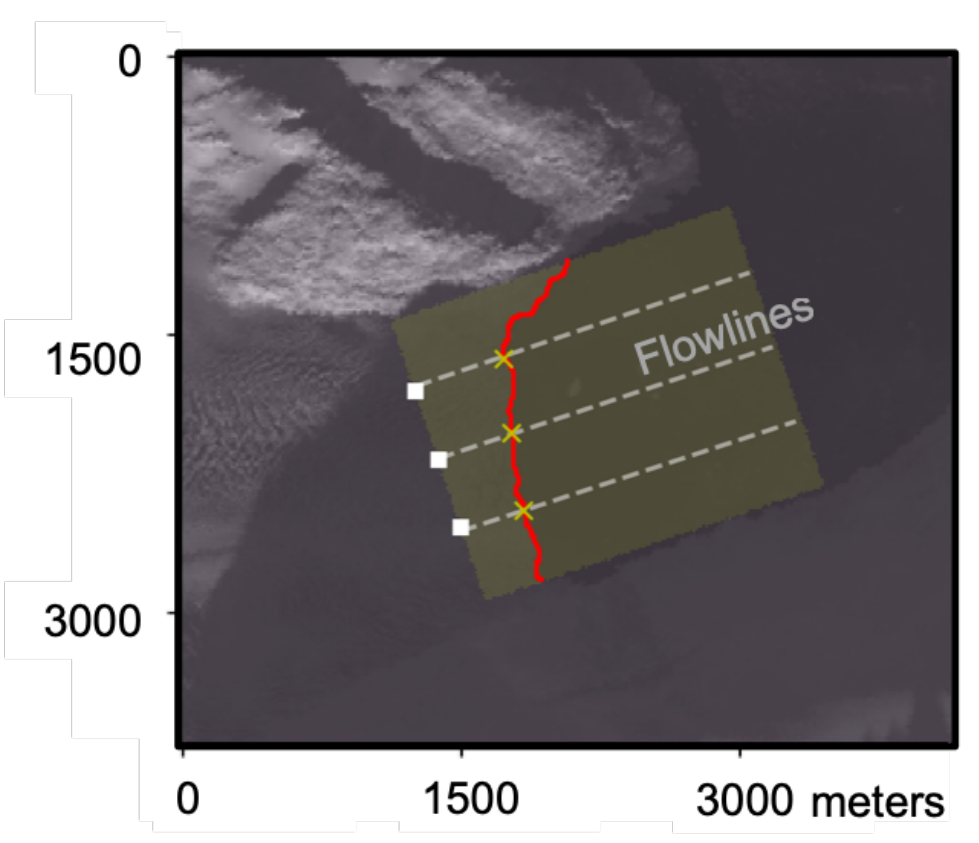

Figure 2.6 Three flowlines positioned at one-fourth, one-half, and threefourths of the width of the glaciers terminus box. Terminus position is measured along each flowline as the distance between the intersection of the delineation with the flowline (yellow $X \mathrm{~s}$ ) and the point on the left side of the box (white squares). 
vative threshold of 3 times the maximum flow speed in order to account for temporal variations in glacier velocities. The same threshold is applied to points that yield a high rate of terminus retreat if followed by rate of advance that violates the flow speed condition. The filtering is repeated 3 times, with the terminus change rates recalculated after each iteration. If multiple terminus position points remain for one time point, the point associated with the highest metric value is chosen to represent the terminus position at that time point. Terminus positions along each flowline are filtered separately.

The final products are filtered time series that show changes in terminus position at sub-seasonal time scales (Fig. 2.7). The time series allows for observation of patterns in seasonal glacier retreat from April through October as well as multiannual trends in retreat over the 2013-2020 period. The automated method is able to resolve a variety of glacier terminus advance and retreat regimes.

\subsection{Evaluation of the method performance}

I evaluated the automated method's accuracy in comparison to the dataset of manual delineations, with consideration of the various environmental and image conditions shown in Figure 2.8 and Table 2.1 (clear, bright and dim lighting, thin cloud presence, sea ice presence, and shadow presence, etc.). The automated-manual differences can be compared to the manual-manual differences in delineation. The manual-manual differences in terminus positions were determined experimentally from two human analysts delineating the same $n=50$ images. Experiments yielded a standard deviation in manual delineation of \pm 31.0 meters or $\sim 2$ pixels. The accuracy of the automated method on an image-by-image basis, referred to from now onwards as the point uncertainty, was calculated using the misfit as defined in Eq. 2.8). Table 2.1 


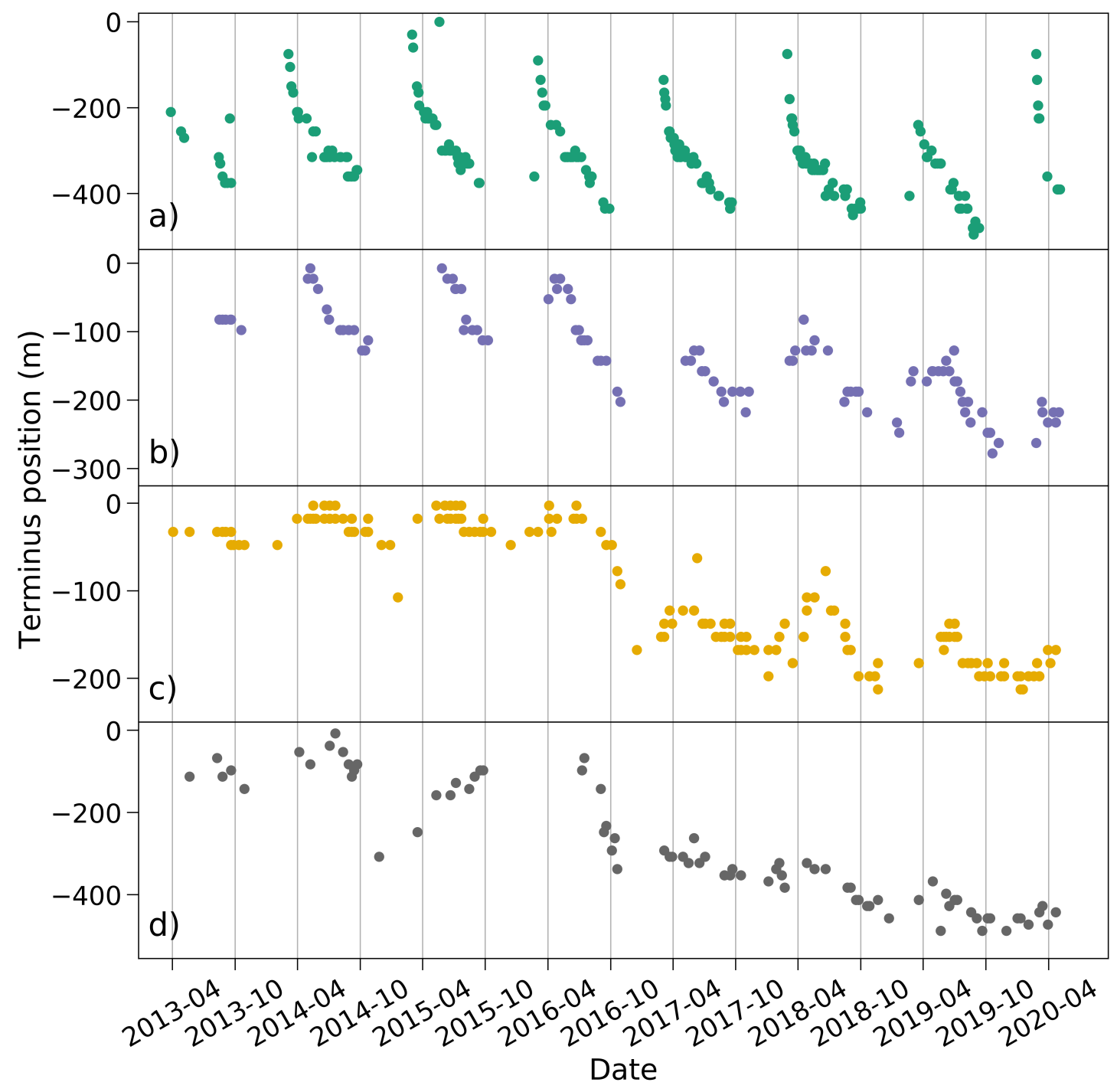

Figure 2.7 Landsat-8 time series (2013-2020) of terminus position along the center flowline for four test glaciers. RGI ID and center latitude and longitude for the four glaciers shown: (a) RGI50-05.08015 $\left(77.1825^{\circ} \mathrm{N}\right.$, $\left.69.9648^{\circ} \mathrm{W}\right)$, (b) RGI50-05.08054 $\left(76.8639^{\circ} \mathrm{N}, 67.5921^{\circ} \mathrm{W},(\mathrm{c})\right.$ RGI50-05.03806 (60.9779 $\left.{ }^{\circ} \mathrm{N}, 43.3386^{\circ} \mathrm{W}\right)$, and (d) RGI50-05.05257 $\left(61.6578^{\circ} \mathrm{N}, 42.7686^{\circ} \mathrm{W}\right)$. 
shows the median misfits between the automated and manual delineations by image condition for both the $10 \%$ (52 out of the 512 - see section 2.5.2) of manual delineations excluded from the optimization algorithm development and the full manual dataset.

Table 2.1 Median misfit values $\left(X_{\text {diff }}\right) \pm$ one median of absolute difference (MAD) by image condition for the cross-validation dataset $(n=$ $51)$ and the full dataset $(n=512)$.

\begin{tabular}{|l|l|l|}
\hline & \multicolumn{2}{|c|}{$X_{\text {diff }}(\mathrm{m})$} \\
\hline Image condition & Cross-validation dataset & Full dataset \\
\hline Clear & $12.2 \pm 5.9(n=21)$ & $17.6 \pm 9.7(n=229)$ \\
Bright or dim lighting & $10.6 \pm 9.5(n=5)$ & $11.5 \pm 9.7(n=25)$ \\
Thin clouds present & $1.7 \pm 1.7(n=3)$ & $24.5 \pm 15.3(n=23)$ \\
Sea ice present & $74.9 \pm 58.1(n=18)$ & $73.4 \pm 33.2(n=206)$ \\
Shadows present & $91.7 \pm 71.7(n=4)$ & $25.7 \pm 15.0(n=29)$ \\
\hline
\end{tabular}

Based on these results, the automated method is capable of delineating terminus positions at a similar accuracy to that of manual uncertainties in images that were clear, uniform in brightness (either dim or bright), or contained thin cloud cover (Fig. 2.1e). For clear images, where there is high contrast between the glacier ice and open water (e.g. Fig. 2.8a), the automated method effectively delineated the terminus position within 1-pixel uncertainty from the manual terminus delineation. Due to the method's gradient-based algorithm, it also effectively delineates glacier terminus positions in images that are bright or dim (e.g. Fig. 2.8b,d), with better than 1-pixel uncertainty. When thin clouds cover the terminus (e.g. 2.8e), the gradientbased algorithm is able to resolve the intensity contrast representing the terminus boundary with an accuracy that is less than the inter-analyst uncertainty. The median misfit for these three image conditions was $10.6 \pm 6.4$ meters or $<1$ pixel. Images where the fjord walls cast shadows across the glacier terminus or sea ice, producing a 
higher intensity gradient than the gradient along the terminus, result in delineations along the shadow boundary (Fig. 2.8c). As a result, the images with shadows near the terminus yielded the greatest misfit. However, the misfit is not constant: the movement of the shadow with the gradual change in sun angle over time may result in an apparent increase or decrease in terminus position, as demonstrated by the apparent rapid retreat throughout April in the time series shown in Fig. 2.8a. It may be possible to correct for the shadow-offset using the time of acquisition of the image, the viewing angle of the satellite, and precise knowledge of the surrounding terrain, but I do not explore these more complex methods here. Terminus positions delineated during low sun angle months at high-latitudes should be interpreted with caution, but the automated delineations are robust for delineations in less-challenging lighting conditions.

Sea ice breakup can complicate the delineation of the terminus boundary. The automated method can delineate the terminus boundary when there is sea ice that is cohesive and extends out of the terminus box (see Fig. 2.8g). However, sea ice breakup within the terminus box can present a challenge to delineation, since the high contrast between the bright sea ice and open water is often higher than the contrast between glacier ice and sea ice. For glaciers where gradual seasonal sea ice or mélange breakup is prominent, the automated method may delineate boundaries that are further out than the glacier terminus. Due to our selection of top five maxima chains and our time series filtering using glacier velocities, these false advances are often filtered out (see section 2.6.2). The standard glacier velocity threshold of 3 times the maximum flow speed could be made stricter (e.g. 1 or 2 times the maximum flow speed) for more stringent time series filtering. However, stricter filtering thresholds 

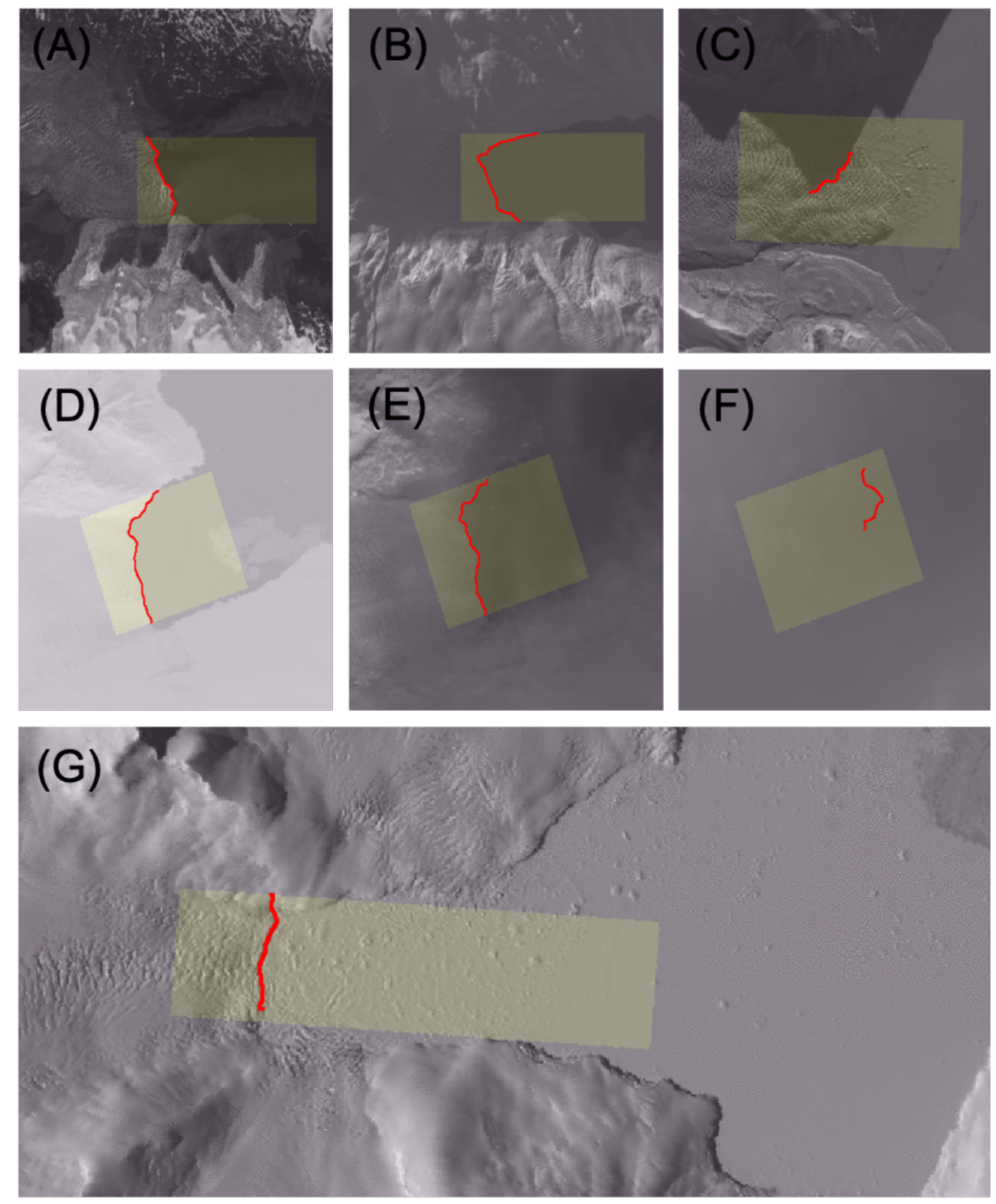

Figure 2.8 Examples of automated delineations from a variety of peripheral glaciers and image conditions. Delineations are the most accurate for the following conditions: (a) a clear image with high intensity contrast between glacier ice and darker ocean water, (b) a dim image, (d) a bright image, and (e) an image with thin cloud cover present. The following conditions present challenges to delineation: (c) partial shadow near calving front and (f) thick cloud cover present. Automated delineation yields mixed results for $(\mathrm{g})$ images with sea ice in front of the terminus. 
require the use of very accurate velocities to avoid loss of temporal resolution that results from over-filtering. I recommend using a conservative speed filtering threshold and performing additional time series filtering outside of the algorithm.

\subsection{Efficiency advantages over manual delineation}

When constructing the manual delineation dataset, I recorded the time required to delineate the images using the Google Earth Engine Digitisation Tool (GEEDiT) (Lea, 2018). The average delineation time required in GEEDiT is 90-150 seconds per image, which is considerably faster than most other manual delineation approaches that require manual download of the satellite images and generation of the polyline object and its attributes in GIS software. Meanwhile, the automated method I developed yields delineations in 70 seconds per image when run in serial. When considering analysis for 100 images required to generate a multi-year time series for one glacier, this equates to $0.5-2.2$ hours of time saved compared to a manual approach for just a single glacier. When the 2D WTMM analysis and subsequent determination of the terminus chain are run in parallel across multiple CPUs, the efficiency increases to 3 seconds per image, which is an order of magnitude faster. The time saved using the parallelized automated delineation approach increases to 2.4-4.1 hours for 100 images. When analyzing multiple glaciers over a several year time period (which requires thousands of images), using the automated method saves time on the order of days to weeks.

The automated analysis could be further streamlined by reducing the number of spatial scales of 2D WTMM analysis. The automated download of the images prior to automated analysis is the slowest step in the workflow. Future work could explore integration of the automated delineation method into an environment such as Google 
Earth Engine, which allows for analysis of satellite images without download.

\subsection{Conclusions and Future Work}

The use of the adapted 2D WTMM segmentation method for delineation of glacier calving fronts is promising. This automated method is capable of delineating marine glacier calving fronts within 1-pixel uncertainty in images with clear conditions, dim or bright lighting conditions, and thin cloud presence. Images where there are shadows cast off of the fjord walls across the glacier terminus and where there are shadows from ice cliff at the calving front may require manual validation and adjustments. Knowing that two humans do not produce identical delineation lines, our experiments show that the automated method has an uncertainty that is within the inter-human variability. This automated method can be applied to accurately and efficiently resolve subseasonal to multiannual patterns in glacier terminus position change in a variety of image conditions.

The resulting time series of glacier terminus position generated from this method can be used to assess glacier calving front shape changes as well as spatiotemporal patterns in glacier length change. The generated time series are able to capture a range of glacier behavior including gradual advances and retreats, calving, and changes in terminus shape. Immediate future work will focus on extending the workflow to include images from earlier Landsat missions such as Landsat-7 and Landsat5. Future work should explore its application to other image types (satellite radar images and other optical images such as Sentinel-2, etc.), in other regions, and for delineations of other features such as coastlines or closed features such as icebergs and lakes. Adaptation of the method to analyze satellite radar images could be particularly useful for increasing the temporal resolution of these terminus position 
time series, as radar images are not hindered by cloud presence or darkness in polar night. The code used for all image analysis is available as a GitHub repository (https://github.com/julialiu18/automated-glacier-terminus). 


\section{CHAPTER 3:}

\section{OCEAN FORCING ON TERMINUS RETREAT IN SOUTHEAST GREENLAND}

\subsection{Introduction}

Marine-terminating glaciers in the Arctic respond rapidly to climatic and oceanic forcing (Joughin et al., 2008; Andresen et al., 2012). The marine-terminating glaciers in southeast Greenland, particularly, have been observed to undergo rapid retreat in response to oceanic forcing (Seale et al., 2011; Howat et al., 2008; Howat and Eddy, 2011; Walsh et al., 2012; Sole et al., 2011). From 2001-2005, Seale et al. (2011) observed synchronous retreat in marine-terminating glaciers south of $69^{\circ}$ latitude and attributed the retreat to increased transport of warm subtropical waters to the Irminger Current (Seale et al., 2011; Walsh et al., 2012). These warm subtropical waters originate from the North Atlantic and flow north along the western coast of Iceland before reaching the eastern coast of Greenland, where it flows southward. The glaciers north of $69^{\circ}$, beyond the reach of the Irminger Current, remained stable (Seale et al., 2011). Although the precise mechanisms linking ocean warming are unclear and potentially vary between glaciers, subsurface ocean warming increases terminus undercutting caused by submarine melting and reduces resistance to ice flow provided by sea ice and icebergs adjacent to the terminus, resulting in increased rates of ice 
discharge at glacier calving fronts (Benn et al., 2007; Straneo et al., 2012; Catania et al., 2020). Surface melting also contributes to undercutting when it is routed underneath the glacier (as subglacial discharge) and discharged at the glacier's grounding line (Fried et al., 2018; Slater et al., 2018). Subglacial discharge that emerges at the grounding line forms buoyant plumes that entrain the warm subsurface ocean water, enhancing terminus undercutting (Xu et al., 2012; Slater et al., 2018). As such, both increased surface melt from atmospheric warming and warmer subsurface ocean temperatures can drive retreat of Greenland's marine-terminating glaciers (Rignot et al., 2015).

While synchronous terminus retreat attributed to changes in submarine melting has been documented for marine-terminating outlet glaciers draining the southeast portion of the Greenland Ice Sheet, no previous work has documented terminus position changes for the marine-terminating glaciers peripheral to the ice sheet. The lack of observations pertaining to ice-ocean interactions at these peripheral glaciers is due to the abundance of these remote glaciers, which would require considerable time investment to manually delineate, combined with their relatively small contribution to sea level rise relative to the nearby ice sheet and the scarcity of ocean observations near the termini (Carr et al., 2013). Using the automated terminus detection method I developed, I observed synchronous retreat across several marine-terminating peripheral glaciers over a range of latitudes in east Greenland (south of $69^{\circ}$ latitude) over the 2016 melt season. Here I present the results from analysis of 6 peripheral glaciers in southeast Greenland. To explore the drivers of the synchronous terminus retreat, I analyzed vertical ocean profiles measured in NASA's Oceans Melting Greenland (OMG) mission which ran from 2015-2018 and aimed to increase the number of in 
situ fjord and coastal ocean observations to inform studies of ice-ocean interactions (OMG, 2020) and investigated surface melting over the same time period.

\subsection{Synchronous retreat of southeast peripheral glaciers}

The filtered time series of glacier terminus position from 2013-2020 produced by the automated method were fit using 8-term Fourier curves. The time series for 6 peripheral glaciers in southeast Greenland indicate anomalously large retreat over 2016-2017 compared to other years (Fig. 3.1). Several of these glaciers underwent a rapid retreat in 2016 with subsequent stabilization (Fig. 3.1d, f) whereas others continued to retreat gradually after 2017 (Fig. 3.1a,c,e). Large magnitudes of terminus retreat in marine-terminating glaciers in 2016 have been observed elsewhere in the Arctic, including along the west coast of Svalbard near a branch of the Irminger Current (Moholdt et al., 2020).

To explore the statistical significance of the retreat over 2016-17 for each glacier time series, I performed Wilcoxon rank sum tests comparing the mean terminus positions for each year determined by the Fourier fit. Wilcoxon rank sum tests compare two sample means and is robust even with small sample sizes. Low p-values indicate that the two sample means tested are statistically different. The Wilcoxon rank sum tests on the time series of the southeast peripheral glaciers shown in Fig. 3.1 indicate that 5 of the 6 glaciers exhibited statistically different (at the $p<0.001$ level) terminus positions between 2016 and 2017 (Table 3.1). For the glaciers that continued to retreat after the 2016 melt season, there are statistically significant differences in annual terminus positions after 2016-2017 (Table 3.1). 

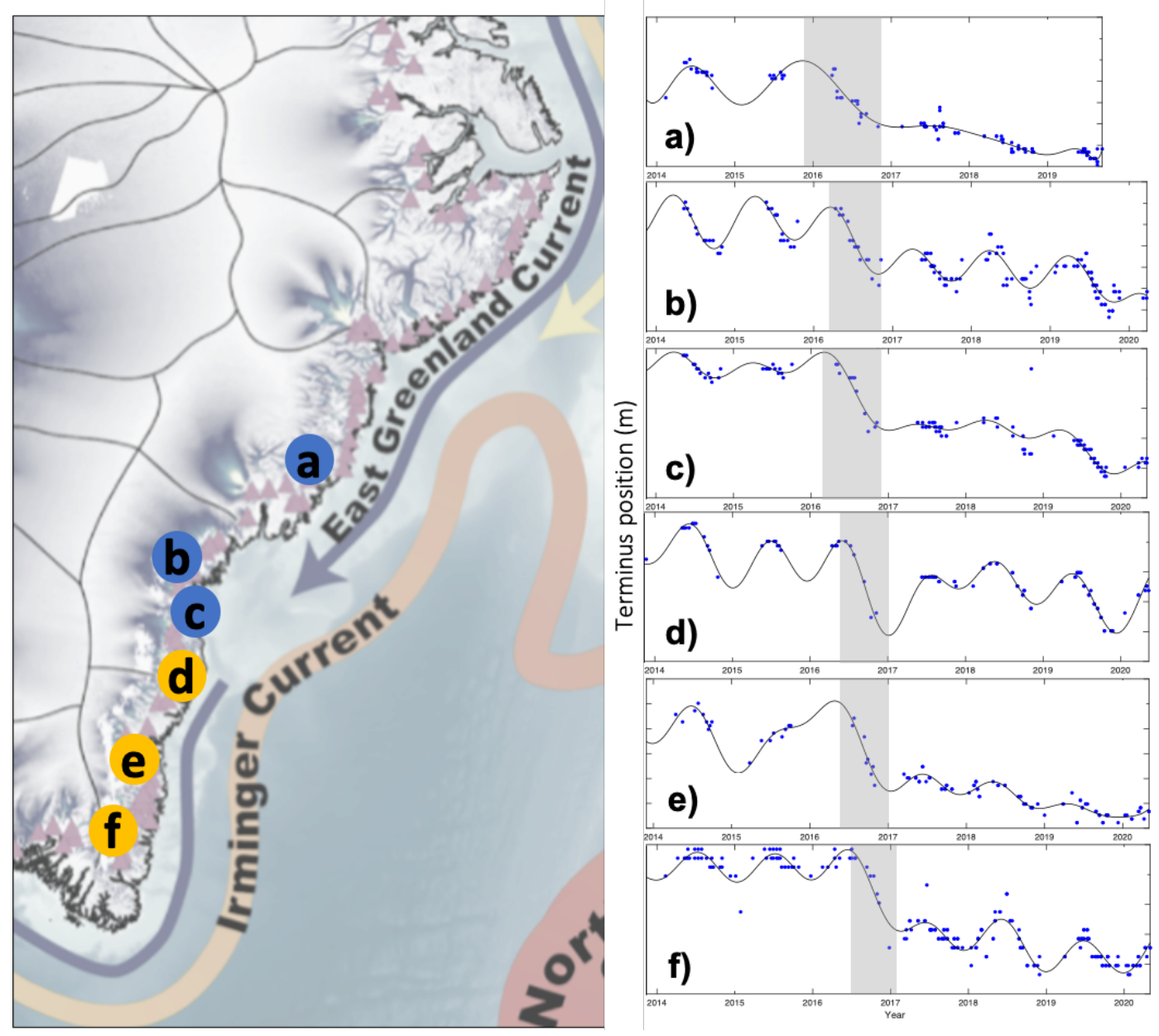

Figure 3.1 Locations of six marine-terminating peripheral glaciers in southeast Greenland exhibiting anomalous retreat from 2016-2017 (adapted from Catania et al. (2020)). Orange bubbles indicate glaciers near the ocean measurements shown in Fig. 3.2. Panels (a)-(f) show the terminus position time series for the glaciers fit using an 8-term Fourier curve. The period of glacier retreat during the $\mathbf{2 0 1 6}$ melt season is high-lighted in gray for each time series. 
Table 3.1 P-values from Wilcoxon rank sum tests of terminus positions for adjacent years in each time series. Glaciers are listed by their panel label (a)-(f) from Fig. 3.1. Statistical significance is indicated as follows: - for $p>$ $0.05, *$ for $p<0.05, * *$ for $p<0.01, * * *$ for $p<0.001, * * * *$ for $p<0.0001$.

\begin{tabular}{|l|l|l|l|l|l|l|}
\hline & \multicolumn{7}{|c|}{ Glacier } \\
\hline Years compared & a & b & c & d & e & f \\
\hline 2013 to 2014 & $* *$ & - & - & ** & - & $* *$ \\
\hline 2014 to 2015 & $*$ & - & - & - & - & - \\
\hline 2015 to 2016 & $* * *$ & $*$ & $*$ & - & - & - \\
\hline $\mathbf{2 0 1 6}$ to 2017 & $* * * *$ & $* * * *$ & $* * * *$ & - & $* * * *$ & $* * * *$ \\
\hline 2017 to 2018 & $* * * *$ & - & - & - & $* * * *$ & - \\
\hline 2018 to 2019 & $* * * *$ & $* *$ & $* * * *$ & $*$ & $* * * *$ & $* * * *$ \\
\hline 2019 to 2020 & no data & - & - & - & - & $* *$ \\
\hline
\end{tabular}

Another notable pattern is the apparent time lag in the onset of glacier terminus retreat from north to south (see gray highlighted retreat from Fig. 3.1a down to 3.1f), which suggests the influence of the timing of warm water transport along the Irminger Current following the southeast coast of Greenland. If this glacier retreat was driven by surface melting, the retreat time lag would move from south to north due to the inverse relationship between air temperature and latitude. This north-south lag in retreat timing also suggests that these peripheral glaciers' retreat are influenced by the southward flowing coastal currents along the coast of east Greenland. I initiated exploration of both ocean and atmospheric drivers of these glaciers' retreat.

\subsection{Ocean temperature changes from 2016-2018}

I analyzed ocean properties measured near these peripheral glaciers in southeast Greenland to explore the influence of ocean-forcing on their retreat in 2016-2017. The ocean measurements from OMG were focused in northwest Greenland in 2015. After 2015, Airborne eXpendable Conductivity Temperature Depth (AXCTD) in- 


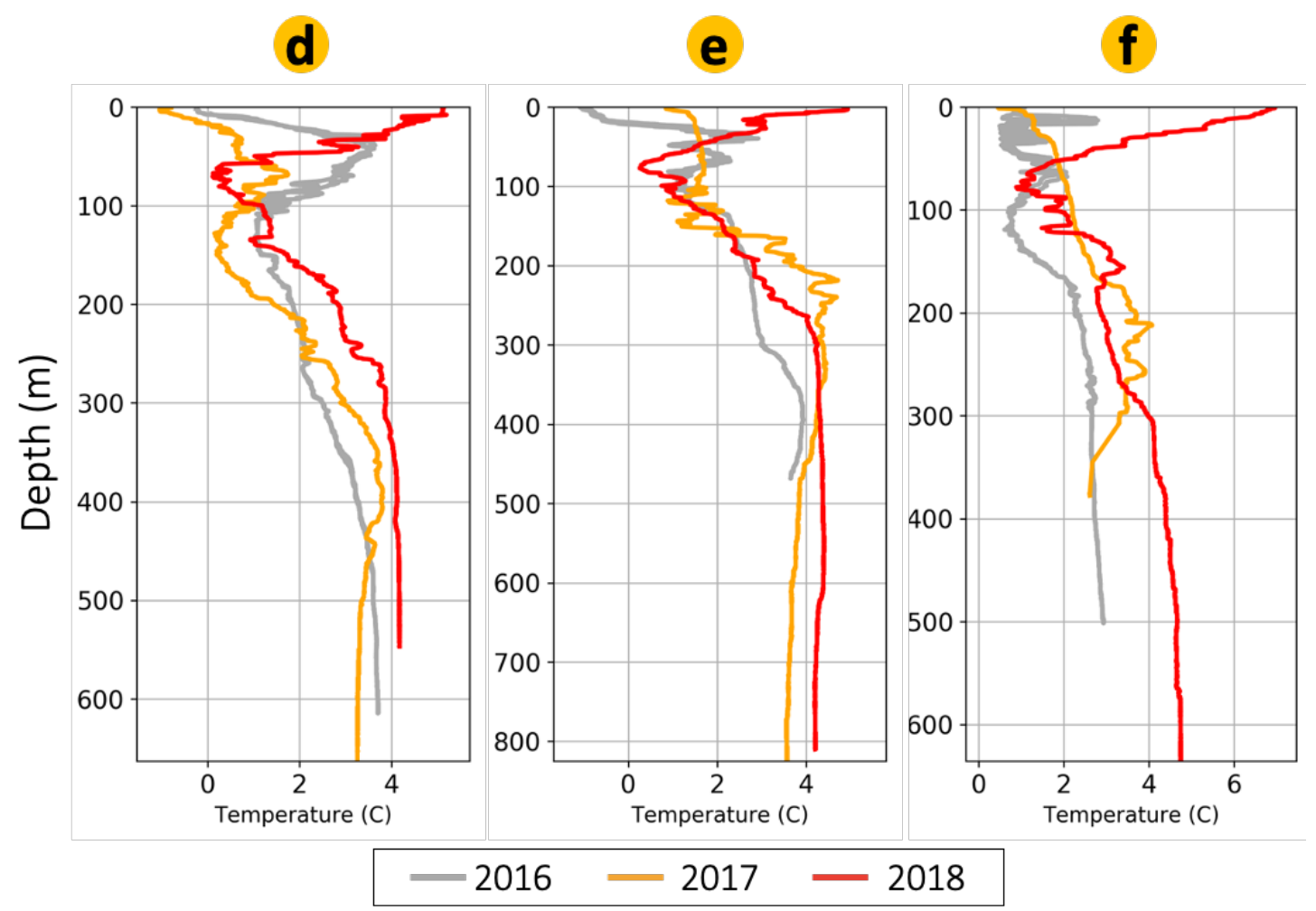

Figure 3.2 Annual vertical ocean temperature measurements from OMG over 2016-2018 near three of the six peripheral glaciers (see Fig. 3.1 for locations). Temperature profiles indicate that subsurface waters $(<200$ meters below sea level) are warmer after 2016.

struments were deployed over west and east Greenland to measure ocean properties close to the coasts of Greenland, while AML Oceanographic Minos X CTD Teledyne Oceanscience Underway CTD instruments aboard sea vessels were used to make ocean measurements within the fjords (OMG, 2020). The CTD measurements closest to the peripheral glaciers indicate that subsurface water temperatures were up to $1^{\circ} \mathrm{C}$ warmer in 2018 than in 2016 (Fig. 3.2), which is a substantial amount of warming when considering subsurface ocean temperatures. Warming of subsurface ocean waters after 2016 could be contributing to these glaciers' rapid retreat over 2016-2017 
and subsequent retreat.

\subsection{Influence of surface melting}

Initial investigation into Greenland surface melt over this time period suggests that 2016 was a high-melt year. Runoff measurements at the Watson River in west Greenland from Polar Portal (http://polarportal.dk/en/greenland/surface-conditions/) indicate that annual runoff was greater in 2016 than any other year from 2013-2018 and around twice as great in 2016 compared to 2013, 2015, 2017, and 2018 (DMI et al., 2018). These observations suggest that increased subglacial discharge from surface melt in 2016 could have contributed to the rapid retreat observed in the southeastern glaciers in 2016. I plan to use modeled surface mass balance data from the Regional Atmospheric Climate Model (RACMO) to formally investigate changes in surface melt in southeast Greenland from 2013 to 2019. Analysis of the gridded surface mass balance data generated by RACMO will confirm whether surface melting of these peripheral glaciers was substantially larger over 2016-2017.

\subsection{Conclusions and Future Work}

With the time series generated from my automated method, I uncovered evidence for synchronous retreat of these marine-terminating peripheral glaciers in southeast Greenland over 2016-2017. Initial investigation of ocean temperatures and surface runoff suggests that these southeastern glaciers did experience warmer subsurface ocean temperatures and greater runoff from surface melt in 2016. I will explore oceanforcing on southeast peripheral glacier retreat in further depth through analysis of additional ocean data available through the OMG mission as well as data from ocean models. Expanding the automated terminus position analysis to include a greater 
proportion of peripheral glaciers (265 total) in southeast Greenland may provide additional evidence for synchronous glacier retreat from 2016-2017. In addition, I will examine surface mass balance data generated from the RACMO over this time period to further investigate atmospheric drivers of these glaciers' retreat. Lastly, I intend to explore the influence of the Irminger Current water transport on the timing of the onset of peripheral glacier retreat, which occurs later in the melt season for glaciers further south. Exploration of these environmental factors will provide insight on the dynamics controlling these peripheral glaciers' terminus changes. 


\section{REFERENCES}

2017. Randolph Glacier Inventory: A Dataset of Global Glacier Outlines: Version 6.0 .

2020. Oceans Melting Greenland Conductivity, Temperature and Depth (CTD) data from the ocean survey. Ver. 0.1.

Andresen, C. S., Straneo, F., Rivergaard, M., Bjørk, A. A., Andersen, T. J., Kuijpers, A., Nørgaard-Pedersen, N., Kjær, K. H., Schjøth, F., Weckström, K., and Ahlstrøm, A. P. 2012. Rapid response of Helheim Glacier in Greenland to climate variability over the past century. Nature Geoscience, 5, 37-41.

Batchelder, K. A., Tanenbaum, A. B., Albert, S., Guimond, L., Kestener, P., Arneodo, A., and Khalil, A. 2014. Wavelet-based 3D reconstruction of microcalcification clusters from two mammographic views: New Evidence that fractal tumors are malignant and Euclidean tumors are benign. PLoS ONE, 9(9), e107580.

Benn, D. I., Warren, C. R., and Mottram, R. H. 2007. Calving processes and the dynamics of calving glaciers. Earth Science Reviews, 82, 143-179.

Carr, J. R., Stokes, C. R., and Vieli, A. 2013. Recent progress in understanding marine-terminating Arctic outlet glacier response to climatic and oceanic forcing: Twenty years of rapid change. Progress in Physical Geography, 37-436. 
Catania, G. A., Stearns, L. A., Moon, T., Enderlin, E., and Jackson, R. H. 2020. Future evolution of Greenland's marine-terminating outlet glaciers. Journal of Geophysical Research: Earth Surface, 125, e2018JF004873.

Cook, A. J., Holland, P. R., Meredith, M. P., Murray, T., Luckman, A., and Vaughan, D. G. 2016. Ocean forcing of glacier retreat in the western Antarctic Penninsula. Science, 353(6296).

Cook, A. J., Copland, L., Noël, B. P. Y., Stokes, C. R., Bentley, M. J., Sharp, M. J., Bingham, R. G., and van den Broeke, M. R. 2019. Atmospheric forcing of rapid marine-terminating glacier retreat in the Canadian Arctic Archipelago. Science Advances, 5, eaau8507.

DMI, GEUS, and DTU. 2018. Polar Portal from the Danish Meteorological Institute (DMI) and The Geological Survey of Denmark and Greenland (GEUS) and National Space Institute (DTU).

Enderlin, E. M., Howat, I. M., Jeong, S., Noh, M., Angelen, J. H. Van, and van den Broeke, M. R. 2014. An improved mass budget for the Greenland Ice Sheet. Geophysical Research Letters, 41, 866-872.

Fried, M. K., Gatania, G. A., Stearns, L. A., Sutherland, D. A., Bartholomaus, T. C., Shroyer, E. L., and Nash, J. D. 2018. Reconciling drivers of seasonal terminus advance and retreat at thirteen central west Greenland tidewater glaciers. Journal of Geophysical Research: Earth Surface, 123, 15901607.

Gardner, A. S., Moholdt, G., Cogley, J. G., Wouters, B., Arendt., A. A., Wahr, J., Berthier, E., Hock, R., Pfeeffer, W. T., Kase, G., Ligtenberg, S. R. M., Bolch, T., 
Shapr, M. J., Hagen, J. O., van den Broeke, M. R., and Paul, F. 2013. A Reconciled Estimate of Glacier Contributions to Sea Level Rise: 2003 to 2009. Science, 340, $852-857$.

Grant, J., Verrill, C., Coustham, V., Arneodo, A., Palladino, F., Monier, K., and Khalil, A. 2010. Perinuclear distribution of heterochromatin in developing C. elegans embryos. Chromosome Research, 18, 837-855.

Howat, I. M., and Eddy, A. 2011. Multi-decadal retreat of Greenlands marineterminating glaciers. Journal of Glaciology, 57, 389396.

Howat, I. M., Joughin, I., Tulaczyk, S., and Gogineni, S. 2005. Rapid retreat and acceleration of Helheim Glacier, east Greenland. Geophysical Research Letters, $\mathbf{3 2}(22)$.

Howat, I. M., Box, J. E., Ahn, Y., Herrington, A., and McFadden, E. M. 2010. Seasonal variability in the dynamics of marine-terminating outlet glaciers in Greenland. Journal of Glaciology, 56(198).

Howat, I.M., Joughin, I., Fahnestock, M., Smith, B.E., and Scambos, T. 2008. Synchronous retreat and acceleration of southeast Greenland outlet glaciers 2000-2006: ice dynamics and coupling to climate. Journal of Glaciology, 54(187), 646-660.

IPCC. 2014. Climate Change 2014: Synthesis Report. Contribution of Working Groups I, II and III to the Fifth Assessment Report of the Intergovernmental Panel on Climate Change. 0-151.

Joughin, I., Howat, I. M., Alley, R. B., et al. 2008. Ice-front variation and tidewa- 
ter behaviour on Helheim and Kangerdlugssuaq Glaciers, Greenland. Journal of Geophysical Research, 113, F01004.

Joughin, I., Smith, B., Howat, I., and Scambos, T. 2016. MEaSUREs Multi-year Greenland Ice Sheet Velocity Mosaic, Version 1.

Joughin, I., Smith, B., and Howat, I. 2017. A complete map of Greenland ice velocity derived from satellite data collected over 20 years. Journal of Glaciology, 64(243), $1-11$.

Kestener, P., Conlon, P. A., Khalil, A., Fennell, L., McAteer, R. T. J., Gallagher, P. T., and Arneodo, A. 2010. Characterising Complexity in Compound Systems: Segmentation in Wavelet-Space. Astrophysical Journal, 717, 995-1005.

Khalil, A., Grant, J. L., Caddle, L. B., Atzema, E., Mills, K. D., and Arneodo, A. 2007. Chromosome territories have a highly nonspherical morphology and nonrandom positioning. Chromosome Research, 15, 899-916.

King, M. D., Howat, I. M., Jeong, S., Noh, M. J., Wouters, B., Noël, B., and van den Broeke, M. R. 2018. Seasonal to decadal variability in ice discharge from the Greenland Ice Sheet. The Cryosphere, 12, 3813-3825.

Lea, J. M. 2018. Google Earth Engine Digitisation Tool (GEEDiT), and Margin change Quantification Tool (MaQiT) simple tools for the rapid mapping and quantification of changing Earth surface margins. Earth Surf. Dynam.

Marin, Z., Wallace, J. K., Nadeau, J. L., and Khalil, A. 2017. Wavelet-based tracking of bacteria in unreconstructed, off-axis holograms. Methods, 136, 60-65. 
McAteer, R. T. J., Kestener, P., Arneodo, A., and Khalil, A. 2010. Automated detection of coronal loops using a wavelet transform modulus maxima method. Solar Physics, 262, 387-397.

McFadden, E. M., Howat, I. M., Joughin, I., Smith, B. E., and Ahn, Y. 2011. Changes in the dynamics of marine terminating outlet glaciers in west Greenland (2000-2009). Journal of Geophysical Research, 116, F02022.

McNabb, R. W., and Hock, R. 2014. Alaska tidewater glacier terminus positions, 1948-2012. Journal of Geophysical Research, 119, 152-167.

Meire, L., Mortensen, J., Meire, P., Juul-Pedersen, T., Sejr, M. K., Rysgaard, S., Nygaard, R., Huybrechts, P., and Meysman, F. J. R. 2017. Marine-terminating glaciers sustain high productivity in Greenland fjords. Global Change Biology, 23(12), 5344-5357.

Moholdt, G., Kohler, K., Morris, A., Maton, J., Gardner, A., and Fürst, J. 2020. Recent increase in marine ablation of Svalbard glaciers. Presentated at the International Arctic Science Committee (IASC) Annual Workshop on the dynamics and mass budgets of Arctic glaciers in Obergurgl, Austria.

Moon, T., and Joughin, I. 2008. Changes in ice front position on Greenlands outlet glaciers from 1992 to 2007. Journal of Geophysical Research, 113, F02022.

Nishizawa, B., Kanna, N., Abe, Y., Ohashi, Y., Sakakibara, D., Asaji, I., Sugiyama, S., Yamaguchi, A., and Watanuki, Y. 2020. Contrasting assemblages of seabirds in the subglacial meltwater plume and oceanic water of Bowdoin Fjord, northwestern Greenland. ICES Journal of Marine Science, 77, 711-720. 
Rignot, E., Fenty, I., Xu, Y., Cai, C., and Kemp, C. 2015. Undercutting of marine-terminating glaciers in West Greenland. Geophysical Research Letters, 42, 59095917.

Roland, T., Khalil, A., Tanenbaum, A., Kerguiga, L., Delichére, P., Bonneviot, L., Elezgaray, K., Arneodo, A., and Argoul, F. 2009. Revisiting the physical processes of vapodeposited thin gold films on chemically modified glass by atomic force and surface plasmon microscopies. Surface Science, 603, 3307-3320.

Seale, A., Christoffersen, P., Mugford, R. I., and O'Leary, M. 2011. Ocean forcing of the Greenland Ice Sheet: Calving fronts and patterns of retreat identified by automatic satellite monitoring of eastern outlet glaciers. Journal of Geophysical Research, 116, F03013.

Slater, D., Straneo, F., Das, S., Richards, C., Wagner, T., and Nienow, P. 2018. Localized plumes drive frontwide ocean melting of a Greenlandic tidewater glacier. Geophysical Research Letters, 45(12), 35012,358.

Sole, A. J., Mair, D. W., W., Nienow P., et al. 2011. Seasonal speedup of a Greenland marine-terminating outlet glacier forced by surface melt-induced changes in subglacial hydrology. Journal of Geophysical Research, 116, F03014.

Straneo, F., Curry, R. G., Sutherland, D. A., Hamilton, G. S., Cenedese, C., Våge, K., and Stearns, L. 2011. Impact of fjord dynamics and glacial runoff on the circulation near Helheim Glacier. Nature Geoscience, 4, 322-327.

Straneo, F., Heimbach, P., Segienko, O., Hamilton, G., Catania, G., Griffies, S., Hallberg, R., Jenkins, A., Joughin, I., Motyka, R., Pfeffer, W. T., Price, S. F., Rignot, 
E., Scambos, R., Truffer, M., and Vieli, A. 2012. Challenges to Understanding the Dynamic Response of Greenland's Marine Terminating Glaciers to Oceanic and Atmospheric Forcing. Bulletin of the American Meteorological Society, 94, $1131-1144$.

Walsh, K. M., Howat, I. M., Ahn, Y., and Enderlin, E. M. 2012. Changes in the marine-terminating glaciers of central east Greenland, 2000-2010. The Cryosphere, 6, 211-220.

Xu, Y., Rignot, E., Menemenlis, D., and Koppes, M. 2012. Numerical experiments on subaqueous melting of Greenland tidewater glaciers in response to ocean warming and enhanced subglacial discharge. Annals of Glaciology, 53(60), 229-234. 